\title{
EVIDÊNCIA DE FEROMÔNIO DE AGREGAÇÃO E CICLO DE VIDA DO CARUNCHO-DO-CAFÉ, Araecerus fasciculatus (Degeer, 1775) (COLEOPTERA: ANTHRIBIDAE)
}

\author{
JOSÉ POLEZE SOARES NOVO \\ Engenheiro Agrônomo
}

Orientador: Prof. Dr. GILBERTO CASADEI DE BAPTISTA

\begin{abstract}
Tese apresentada à Escola Superior de Agricultura "Luiz de Queiróz",da Universidade de Såo Paulo, para obtençăo do título de Doutor em Ciências, Área de Concentraçăo: Entomologia
\end{abstract}

\author{
$P \mid R A C I C A B A$ \\ Estado de São Paulo - Brasil \\ Novembro - 1994
}


Ficha catalografica preparada pela Seça de Livros da Divisao de Biblioteca e Documentaçao - PCLQ/USP Novo, José Poleze Soares

N945e Evidência de feromônio de agregaça e ciclo de vida do caruncho-do-cafe, Araecerus fasciculatus (Degeer, 1775) (Coleoptera: Anthribidae). Piracicaba, 1994. $75 p$. ilus.

Tese - ESALQ

Bibliografia.

1. Café - Praga - Manejo 2. Caruncho-do-café - Comportamento 3. Feromônio de inseto 4. Inseto - Comunicaçao quimica I. Escola Superior de Agricultura Luiz de Queiroz, Piracicaba

$$
\begin{aligned}
& \text { CDD } 632.76 \\
& 632.73
\end{aligned}
$$




\title{
EVIDÊNCIA DE FEROMÔNIO DE AGREGAÇĀO E CICLO DE VIDA DO CARUNCHO-DO-CAFÉ, Araecerus fasclculatus (Degeer, 1775) (COLEOPTERA: ANTHRIBIDAE)
}

\author{
JOSÉ POLEZE SOARES NOVO
}

Aprovada em 02.02.1995

Comissão Julgadora:

Prof. Dr. Gilberto Casadel de Baptista

ESALQ/USP

Prof. Dr. Evaldo Ferreira Vileia

DBAUFV

Dr. Celso Omoto

ESALQ/USP

Dr. André Luiz Lourençăo

IAC/SANSP

Dr. Valdir Atsushi Yuki

IAC/SANSP

Prof. Dr. GHBERT CASADEI DE BAPTISTA Orientador 
A

MARIA DO CARMO, CAROLINA E BRUNO 


\section{AGRADECIMENT08}

Ao Prof. Dr. Gilberto Casadel de Baptista, do Departamento de Entomologia da ESALQ/USP, pela amizade, estímulo e orientaçăo.

Ao Prof. Dr. Octávio Nakano, do Departamento de Entomologia da ESALQ/USP, pelas sugestóes no estudo de comportamento de insetos.

Aos Professores do Departamento de Entomologia da ESALQ/USP, pelos ensinamentos.

Ao 8r. José Benedito Paduane11o, do Instituto Biológico, pela amizade e colaboraçăo.

Aos académicos Vania Maria vieira de Mello, Regina Mitie Kazama a Fernando sousa de camargo Pinto, pela colaboraçâo.

Aos Institutos Biológico e Agronómico (IAC), pelas condiçôes oferecidas.

Ao CNPq pela concessâo de Bolsa de Estudos. 


\section{BUMÁRIo}

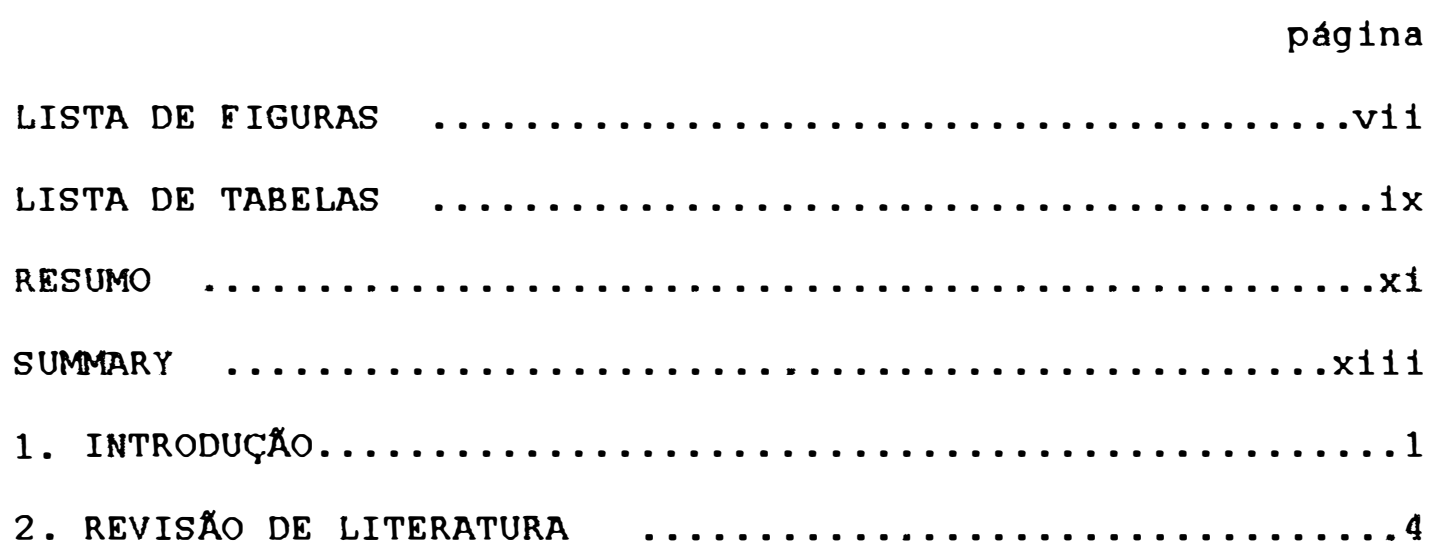

2.1. Araecerns fasciculatus $\ldots \ldots \ldots \ldots \ldots \ldots \ldots$

2.1.1. Distribuição geográfica e hospedeiros ....4

2.1.2. Danos ao café armazenado $\ldots \ldots \ldots \ldots \ldots \ldots$

2.1.3. Biologia e comportamento $\ldots \ldots \ldots \ldots \ldots \ldots \ldots$

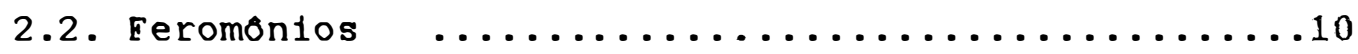

2.2.1. Consideraçoes gera1s $\ldots \ldots \ldots \ldots \ldots \ldots \ldots$

2.2.2. Feromónios em coleopteros pragas de grăos

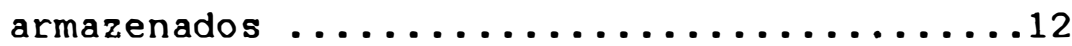

2.3. Bioensaios no estudo do feromónios de insetos .....17 2.3.1. Influência de fatores ambientais .......19

2.3.2. Influencia de fatores biologicos $\ldots \ldots \ldots .23$

2.3.3. Tipos de olfatómetros $\ldots \ldots \ldots \ldots \ldots \ldots \ldots$

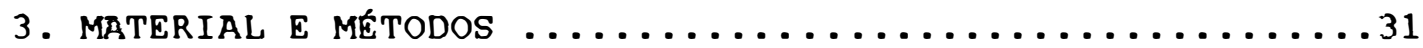

3.1. Criaçăo de A. fasciculatas $\ldots \ldots \ldots \ldots \ldots \ldots \ldots \ldots \ldots$

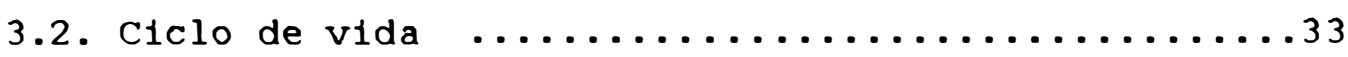

3.3. Preparaçăo e realizaçăo dos bioensaios .........34 3.3.1. Sexagem e manutençăo dos adultos .......34 
3.3.2. Determinaçðo da idade de acasalamento ...37 3.3.3. Bioensaios para avaliaçăo de feromónios ...38

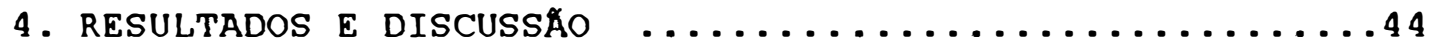
4.1. Ciclo de vida de X. fascicalatas ...........44 4.2. Idade da cópula ....................45 4.3. Feromonios ........................49

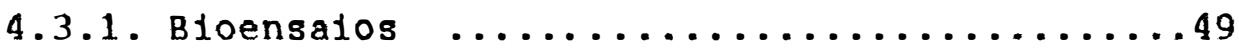

4.3.2. Atratividade de voláteis de fémeas adultas..50 4.3.3. Atratividade de voláteis de machos adultos..53

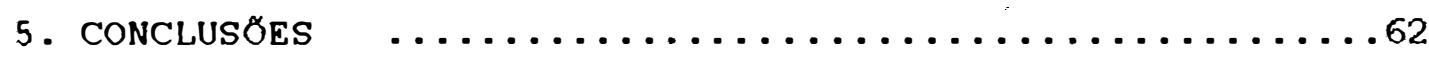
6. REFERENCIAS BIBLIOGRAFICAS $\quad \ldots \ldots \ldots \ldots \ldots \ldots \ldots \ldots$ 
FIGURA 1. Sistema de umidificação utilizado na criaçăo de A. fasctoulatas ................. 32

FIGURA 2. Diferenciaçao de sexos de $A$. fasciculatus por características morfológicas da regiăo posterior do abdome de adultos (EL SAYED,

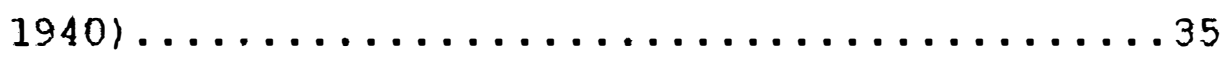

FIGURA 3.Mesa de microscópio binocular utilizada para a sexagem de $A$. fasciculatus...........36

FIGURA 4.Olfatómetro utilizado nos bioensaios com

A. fasciculatus .................40

FIGURA 5. Número médio de acasalamentos de machos de A. fascicalatas, de 1 a 10 dias de idade (médias de 10 repetiçסes). Temperatura $27 \pm 2^{\circ} \mathrm{C}$, Umidade relativa do ar $90 \pm 5 \ldots \ldots \ldots 48$

FIGURA 6. Número médio de acasalamentos de femeas de A. fasciculatus, de 1 a 10 dias de idade (médias de 10 repetiçסes). Temperatura $27 \pm 2{ }^{\circ} \mathrm{C}$, Umidade relativa do ar $90 \pm 58 \ldots \ldots 48$

FIGURA 7. Respostas de machos ativos de $\boldsymbol{A}$. fascicalatusde 8 a 10 dias de idade, atraídos por machos de 5 a 10 dias de idade. (medias de 10 repetiçסes). Temperatura $27 \pm 2^{\circ} \mathrm{C}$, Umidade relativa do ar $90 \pm 5 \ldots \ldots \ldots \ldots \ldots \ldots \ldots 5$

FIGURA 8. Respostas de femeas ativas de $\boldsymbol{A}$. fascionlatus de 8 dias de idade, atraidas por machos de 2 a 10 dias de idade. (médias de 10 repetiçós). Temperatura $27 \pm 2^{\circ} \mathrm{C}$, Umidade relativa do ar $90 \pm 5 \ldots \ldots \ldots \ldots \ldots \ldots$ 
FIGURA 9. Resposta de femeas ativas de A. fascionlatas de 3 a 10 dias de idade, atraídas por machos de 8 dias. (medias de 10 repetições). Temperatura $27 \pm 2^{\circ} \mathrm{C}$, Umidade rela-

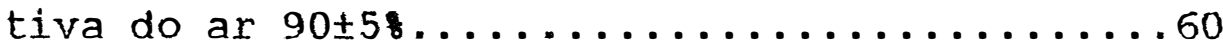


LISTA DE TABELAS

página

TABELA 1. Componentes principais de feromónios de colebpteros de gráos armazenados, citados por BURKHOLDER \& MA, 1985.............13

TABELA 2. Feromónios de coleópteros de gráos armazenados identificados após 1985............15

TABEla 3. Idades (dias) e sexos, dos adultos de A. fasciculatus usados como fonte de volateis e como receptores nos bioensaios realizados...43

TABELA 4. Número de acasalamentos de $A$. Fascicalatas em cada combinação de idades, de 1 a 10 dias. (Número de casais observados em cada

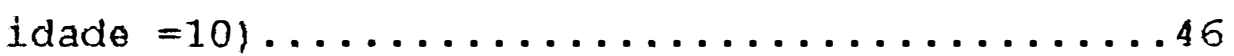

TABELA 5. Respostas de femeas virgens de $A$. fascicalatos de 7 a 9 dias, atraidas por volateis de femeas virgens de 6 a 9 dias (medias de 10 repetiçסes). Temperatura $27 \pm 2{ }^{\circ} \mathrm{C}$, Umidade relativa do ar $90 \pm 58 \ldots \ldots \ldots \ldots \ldots 1$

TABELA 6. Respostas de machos virgens de A. fasctanlatas de 7 a 9 dias, atraldos por volateis de femeas virgens de 7 a 9 dias (medias de 10 repetiçסes). Temperatura $27 \pm 2^{\circ} \mathrm{C}$, Umidade relativa do ar $90 \pm 58 \ldots \ldots \ldots \ldots \ldots 2$

TABELA 7. Respostas de machos virgens de $A$. Fascicalatas de 6 a 10 dias, atraidos por volateis de machos virgens de 5 a 10 dias (médias de 10 repetiçôs). Temperatura $27 \pm 2^{\circ} \mathrm{C}$, Umidade relativa do ar $90 \pm 58 \ldots \ldots \ldots \ldots \ldots . \ldots 4$ 
TABELA 8. Respostas de fomeas virgens de A. fasatonlatus de 3 a 10 dias, atraldas por voláteis de machos virgens de 2 a 10 dias (medias de 10 repetiçős). Temperatura $27 \pm 2^{\circ} \mathrm{C}$, umidade relativa do ar $90 \pm 5 \ldots \ldots \ldots \ldots 7$ 


\section{EVIDÊNCIA DE FEROMÔNIO DE AGREGAÇĀO E CICLO DE VIDA DO CARUNCHO-DO-CAFÉ, Areecerus fasclculatus (Degeer, 1775) (COLEOPTERA: ANTHRIBIDAE)}

Autor: JOSÉ POLEZE SOARES NOVO órientador: DR. GILBERTO CASADEI DE BAPTISTA

RESUMO

Com o objetivo de verificar a ocorrencia de feromónios em Araeceras fascicalatas (Degeer, 1775), estudouse o seu comportamento, em olfatómetro de dupla escolha sem corrente de ar. Os insetos foram criados em graos beneficiados de cafe do cultivar Mundo Novo, com 12 de umidade, em sala mantida a $27 \pm 2{ }^{\circ} \mathrm{C}$, umidade relativa de $90 \pm 58$, e fotofase de 12 horas.

Utilizou-se como fonte de atraçăo, adultos de $\boldsymbol{A}$. fasctculatas recém-emergidos, mantidos em tubos de vidro com uma camada de algodăo e um grăo de café, por períodos de 1 a 10 dias. Como testemunha foram usados tubos identicos, sem os adultos. Nos bioensaios foram usados insetos adultos virgens, sexados no dia da emergencia, e mantidos separados por períodos de 1 a 10 dias. Os bioensaios foram realizados entre 
9 e 11 horas, no escuro, ficando os insetos por um período de 15 minutos no olfatómetro, para condicionamento. o período de atraçăo teve duração de 40 minutos. Foram ainda determinadas a idade da cópula, observando-se insetos de 1 a 10 dias de idade e a duraçăo do ciclo.

o ciclo de vida do inseto, de ovo a adulto variou entre 57 e 97 dias com média de $72,4 \pm 1,0$ dias. A primeira cópula, entre adultos de até cinco dias de idade, ocorreu entre fémeas de 2 dias com macho de 3 dias. O maior número de cópulas ocorreu com femeas de 4 a 9 dias e machos de 5 a 10 dias.

Fêmeas de A. Fasctcalatus năo atraíram machos ou femeas da especie de forma significativa. Machos atrairam tanto femeas quanto machos, havendo atraçăo significativa de machos de 3 dias, atraindo femeas de 3 dias ou mais, e machos de 5 dias ou mais. A porcentagem de femeas que apresentaram respostas, atraidas por machos variou entre 67 e 978, enquanto a de machos variou de 62 a 748 . Os resultados obtidos evidenciam a existencia de feromónio de agregaçăo, produzido pelos machos desta especie. 


\title{
EVIDENCE FOR AN AGGREGATION PHEROMONE AND LIFE CYCLE OF THE COFFEE BEAN WEEVI, Araecerus fasciculatus (Degeer, 1775) (COLEOPTERA: ANTHRIBIDAE)
}

\author{
Author: JOSE POLEZE SOARES NOVO \\ Adviser: DR. GILBERTO CASADEI DE BAPTISTA
}

SUMMARY

The response of adult Araecerus fasctoulatus (Degeer, 1775) (Coffee bean weevil) to volatile stimuli was tested in a closed dual choice pitfall bioassay system, investigating the occurrence of pheromones in this species. A. fasctculatus was reared in green coffee beans (Coffea arabtca cV. Mundo Novo), with a moisture content of 128 , in a climatic room at $27 \pm 2^{\circ} \mathrm{C}, 90 \pm 58 \mathrm{RH}$, and a 12 hours photophase. The source of attraction were newly emerged adults, placed in vials containing a layer of cotton and a single coffee bean. Identical vials were used as controls, without the insect. Test insects were virgin adults, separated by sex on the day of emergence and kept for 1 to 10 days, in the same environmental conditions. The bioassays were conducted between 9:00 and 11:00 AM, in the dark, with a period of 15 minutes of conditioning, and a period of attraction of 40 
minutes. The age of the copula, among 1 to 10 days old insects and the life cycle were also determined.

The life cycle of A. fasclculatas, from egg to adult, extended from 57 to 97 days, with average of $72.4 \pm 1.0$ days. The first copula, among up to 5 days old adults, occurred with 2 days old females and 3 days old males. Most of the females copulated with 4 to 9 days, and males with 5 to 10 days.

A. fascloulatus female did not significantly attracted virgin adults of both sexes. Males attracted both sexes; 3 days old or more showed significant attraction to 3 or more days old females and 5 or more days old males. Sixtyseven to 978 of the responding females, and 62 to 74 of the responding males were attracted to the volatiles of the males. The results evidence the occurrence of a male produced aggregation pheromone in Araeceras tascionlatus. 


\section{INTRODUGĂO}

o estudo de feromónios desenvolveu-se muito nas . últimas décadas, inclusive no Brasil, incentivado principalmente pela possibilidade de uso desses produtos no manejo de pragas, permitindo o monitoramento e o controle atraves do comportamento dos insetos, diminuindo a utilização de produtos tóxicos.

A utilizaçăo de feromonios é uma das técnicas modernas promissoras para o controle de pragas de gráos armazenados (BURKHOLDER \& MA, 1985). Quatro formas de utilizaçăo têm sido mais estudadas: o monitoramento de populaçôes, a coleta massal, a supressåo de acasalamento pelo confundimento e o uso de armadilhas com inseticidas.

Para diversas pragas de grăos armazenados já existem feromónios sintéticos e armadilhas comercialmente disponíveis para monitoramento e coleta massal (ARSURA \& ACCINELLI, 1990 e 1991). A plena utilizaçåo dessas substancias depende ainda de muitos estudos, praticamente em todos os aspectos envolvidos, havendo ainda muitos pontos a elucidar, desde a determinaçăo da existancia de 
feromônios até a esclarecimento do seu modo de açâo, cujo conhecimento poderia permitir o controle atraves da inibição da comunicação.

o caruncho-do-cafe, tambem conhecido como caruncho-das-tulhas, Araeceras fasciculatus (Degeer, 1775) (Coleoptera: Anthribidae) e considerado a principal praga do cafe armazenado no Brasil e, em outros países produtores. Em condiçoes propicias, pode causar severos danos ao cafe armazenado.

O Brasil e o principal produtor mundial de cafe, tendo produzido em 1993, 17,2 milhóes de sacas de cafe beneficiado (LEVANTAMENTO SISTEMATICO DA PRODUÇAO AGRICOLA, 1994). Grande parte de nossa produção e destinada a exportação, e a presença de insetos ou de danos por eles causados pode ate impedir a exportaçáo para paises como os Estados Unidos da America, muito exigentes nesse aspecto.

o uso de feromónios para monitoramento ou controle de pragas de grâos armazenados foi muito pouco estudado no Brasil e até o presente apenas um único trabalho relata a ocorrencia de feromônios liberados pelo caruncho-do-cafe (SINGH, 1993).

Procurando testar a hipotese de que o carunchodo-café utiliza a comunicação química para unir os membros da especie, realizou-se este trabalho, cujos objetivos foram desenvolver um metodo adequado para o estudo do 
comportamento de A. Fasotoulatus em relaçá a feromonios, e determinar a ocorrencia e o tipo de feromonios nesta especie. 


\section{REVISÃO DE LITERATURA}

\subsection{Araecerus fascionlatus}

\subsubsection{Distribuição geográfica e hospedeiros}

o caruncho-do-cafe e um coleóptero da familia Anthribidae, descrito por Carl Degeer ${ }^{1}$ em 1775 como Curoulio fasctoulatus (EL SAYED, 1935). O genero Araecerns foi criado por Schoenherr em 1826, sendo a especie incluida no mesmo, como Araecerus fascioulatus (Degeer, 1775) (BLACKWELDER, 1957).

E um inseto originário da Asia, provavelmente da regiåo que compreende a India e a Malásia, segundo EL SAYED (1935). E considerado cosmopolita, com ampla distribuiçăo, principalmente em regioes tropicais e subtropicais. E um inseto polífago, praga primária de grăos armazenados, sendo registradas infestaçס́es em mais de 136 produtos armazenados e culturas, em cerca de 40 países, segundo levantamento bibliográfico de CHI LDERS \& WOODRUFF (1980).

1 Grafia correta, segundo BLACKWELDER (1957), p. 1045. 
No Brasil, segundo SILVA et al. (1968), A. fascicalatus foi encontrado em sementes e graos de cafe, algodåo, cacau, chá-da-fndia, kuterpe sp, feijao, girassol, milho, tungue e sabal palmeto, atacando ainda manivas e hastes mortas de mandioca, frutos secos ou decompostos de abacaxi, ameixa, figo, marmelo, e ralzes de batata doce armazenadas. Segundo GONÇALVES et al. (1976), ataca também raizes de gengibre, plantas mediclnais secas, farinhas, biscoitos e outros produtos armazenados. IMENES et al. (1993) registraram sua ocorrencia em Raphia pedmoulata, em Jundial, SP.

\subsubsection{Danos ao oafe armazenado}

O caruncho-das-tulhas é a principal praga do café armazenado, no Brasil e em outros países produtores. HEMPEL (1901) o identificou causando danos a café no Estado de Săo paulo, e afirmou que era inseto conhecido já há algum tempo, no Brasil. Segundo EIGUEIREDO Jr. (1957), chega a causar 308 de perdas em um período de 6 meses.

LAVABRE \& DECAZY (1968) verificaram que o café da especie coffea arabioa torna-se muito suscetivel, em ambientes com UR de 808 e temperatura de $25^{\circ} \mathrm{C}$, após 3 meses de armazenamento, chegando a 808 de graos atacados após 9 meses. Os autores verificaram que o cafe robusta resiste ao ataque nestas condiçס̄es, apresentando menos de 1 de grăos 
atacados, após 9 meses. Essa resistencia desaparece quando a umidade relativa é mantida em 1008.

BITRAN (1973) determinou que em um quilo de café, mantido em frasco plástico por 6 meses, com uma infestaçăo inicial de 100 insetos, ocorreu uma perda de 13,78 em peso, com 67,8 dos gráos apresentando danos. Em sacos de juta, com infestaçóes de 17 insetos por quilo no inicio, e acrescentando 8 insetos/quilo aos 30 dias, 17 aos 60 dias, 8 aos 90 dias, 17 aos 120 dias e 8 aos 150 dias, totalizando 75 insetos/quilo, encontrou aos 180 dias, perdas de peso variando de 0,48 a 9,578, com 2,4 a 44,58 de gráos com danos. Aos 9 meses, as perdas de peso ficaram entre 1,72 e 24,638, com 8,1 a 93,58 dos grăos danificados.

Segundo FONSECA (1935), os graos atingidos ainda se prestam para a torrefaçăo, năo havendo alteraçăo da cor, aroma e sabor. BITRAN (1973) verificou que amostras armazenadas em sacos de juta, após 6 meses nao apresentaram alteraçăo no tipo de bebida; entretanto, após 9 meses, o tipo de bebida nâo pode ser determinado pelo fato das amostras encontrarem-se mof adas.

GECAN et al. (1988), em levantamento realizado nos Estados Unidos, em amostras de café importado, encontraram danos causados por insetos (broca-do-cafe e caruncho-do-cafel em 70,68 das amostras, com média de 1,78 dos grăos danificados. As médias de grăos danificados, 
conforme a procedencia das amostras foram, Asia, 3,68, Africa, 2,8 e America do Sul, 1,08.

\subsubsection{Biologia o comportamento}

A biologia do caruncho-do-cafe foi estudada por vários autores. EL SAYED (1935) determinou alguns aspectos em milho, cacau e noz-moscada:

. as condições ideais para o desenvolvimento săo temperatura de $27^{\circ} \mathrm{C}$ e umidade relativa do ar de 90 a 1008 ;

.a razáo sexual em milho é de $1: 1$ e em noz moscada de $1: 1,3$;

- a maturaçăo sexual dos machos deu-se aos 3 dias de vida e das femeas aos 6 dias;

- a cópula ocorre aos 6 dias após a emergencia e dura de 6,5 a 8 minutos. Femeas podem copular mais de uma vez, mas uma é suficiente para que todos os seus ovos sejam ferteis;

. o período de incubaçăo foi de 5-8 dias em umidades relativas de 50 - 1008 ;

. o número de ovos/femea em milho variou de 42 a 125, com média de 79. A umidade tem influencia no número de 
ovos e em sua viabilidade. A viabilidade variou de 678 em 608 UR a 988 em 1008 UR;

. o ciclo de vida mínimo em milho, a $27^{\circ} \mathrm{C}$, variou de 29 dias em umidade relativa de 1008 a 57 dias em 608 UR, que foi considerado o limite mínimo de umidade para desenvolvimento em milho e tambem em noz moscada, onde o ciclo variou de 38 dias em 1008 UR a 69 dias em 608 UR. Em cacau o limite mínimo de umidade foi de 808 UR, com um ciclo de vida de 66 dias; em 1008 UR, o ciclo foi de 37 dias;

. os adultos viveram 27-29 dias a 50 de UR e 86134 dias em UR de 100 .

BRICENO-IRAGORRY (1940), estudando o caruncho em café, estabeleceu a duraçăo do ciclo em 56 dias. CABAL CONCHA (1956) determinou alguns aspectos da biologia do caruncho em cafe, a $28^{\circ} \mathrm{C}$ e 808 de UR:

- cópula aos 4-5 dias, com duraçăo de 5-9 minutos;

- media de 52 ovos/fémea;

- período de incubação de 5-7 dias;

. fase larval de 46-66 dias;

- período pupal de 5-8 dias:

- duração do ciclo de 56-81 dias. 
LAVABRE \& DECAZY (1968), comparando o desenvolvimento em cafe, em umidade relativa de 1008, encontraram ciclos de $28-35$ dias a $30^{\circ} \mathrm{C}, 45-60$ dias a $25^{\circ} \mathrm{C}$ e 53-66 dias a $22^{\circ} \mathrm{C}$. Com 80 UR e $25^{\circ} \mathrm{C}$, o ciclo foi de $65-$ 90 dias, nå havendo nesta umidade diferenças entre arábica e robusta. Em estudos de termo e higropreferencia, verificaram que o btimo de umidade e 908, e que os adultos nao apresentam preferencia por temperaturas, enquanto as larvas preferem temperaturas entre 23 e $33^{\circ} \mathrm{C}$.

No Brasil, AUTUORI (1931) estabeleceu a duraçåo do ciclo em café em 47-63 dias e a idade da primeira cópula em 2-3 dias. O autor apresenta ainda uma descriçăo do comportamento do inseto, principalmente quanto ao acasalamento, posturas e movimentos.

FONSECA (1935), em uma nota sobre o caruncho, apresentou os dados de AUTUORI (1931), entretanto com uma diferença no período de incubaçăo de 1 dia a menos. Autores posteriores consideraram os dados de AUTUORI e FONSECA como trabalhos independentes, com resultados diferentes.

GONÇALVES et al. (1976) determinaram alguns aspectos, em café beneficiado:

- maturação sexual da femea aos 6 dias;

- duraçăo do ciclo:

44-56 dias (temperaturas medias entre 25 e $29^{\circ} \mathrm{C}$ ); 
53-75 dias (temperaturas medias entre 21 e $24^{\circ} \mathrm{C}$ );

. longevidade das fêmeas: 83-114 dias, com média de 50 descendentes por casal.

\subsection{Feromônios}

\subsubsection{Considerą̧ões gerais}

A maioria dos insetos tem necessidade de comunicar-se com outros individuos da mesma especie. Entre individuos que vivem em sociedades, como formigas, cupins e abelhas, essa necessidade de comunicaçăo é mais facilmente compreendida, uma vez que a interaçăo entre eles é fundamental para a manutençăo de uma sociedade complexa. Em individuos solitários a comunicaçăo, embora possa ocorrer somente em algumas fases de sua vida, $b$ igualmente importante, especialmente por permitir a aproximação dos sexos levando à perpetuaçăo das espécies.

Segundo SHOREY (1976), a comunicaçåo biológica envolve a emissão de um ou mais estímulos por um individuo, que provocam uma reaçåo em outro, que pode ser benefica ao emissor, ao receptor ou a ambos. Um estímulo pode agir diretamente causando uma reaçăo no comportamento do receptor ou pode apenas causar alteraçס̃es no nível de resposta do receptor a outros estímulos. 
Diferentes tipos de estimulos podem ser usados na comunicaçåo entre insetos, sendo os principais classificados como quimicos (olfativos ou gustatativos), mecanicos (tácteis ou sonoros) e radiantes (percepçăo de luz ou visuais).

KARLSON \& LUSCHER (1959) propuseram o termo feromónio, definido como "substancias secretadas para o exterior por um individuo e recebidas por um segundo individuo da mesma espécie, no qual provocam uma reaçăo especifica, por exemplo, um comportamento definido ou um processo de desenvolvimento".

Desde a descoberta, isolamento e identificaçăo química do bombicol, o feromonio sexual da mariposa do bicho-da-seda (Bombyx sors), por A. Butenandt (HECKER \& BUTENANDT, 1984), a ecologia química teve um desenvolvimento muito grande. Segundo HUMMEL (1984), mais de oitocentas substancias já haviam sido identificadas e sintetizadas ate entao, graças aos métodos de estudo de comportamento, a disponibilidade de métodos cromatográficos e espectrometricos e de técnicas microquimicas refinadas.

Segundo CAMPIOM (1984), duas classes de feromónios sao mais utilizadas para o controle de pragas: os feromónios sexuais, que aproximam machos e femeas da mesma especie, visando a cópula, e os feromónios de agregaço que aproximam individuos da mesma espécie para 
alimentação e reprodução. Essas duas classes de feromónios estzo intimamente relacionadas, uma vez que ocorrendo a agregaçăo, aumenta a possibilidade de acasalamentos bem sucedidos (VILELA \& DELLA LUCIA, 1987).

2.2.2. Feromónios em coleópteros pragas de grãos armazenados

A partir da identificaçăo do feromonio de Attagenus micolor (Coleoptera, Dermestidae), por SILVERSTEIN et al. (1967), um grande número de insetos de graos armazenados tem sido estudado quanto ao comportamento reprodutivo e à constataçăo e identificaça de feromonios.

BURKHOLDER \& MA (1985) relacionaram insetos de 9 familias, nos quais já haviam sido identificados feromonios, sexuais ou de agregaçao (TABELA 1). Segundo os autores, existiam até entao sete feromonios principais, disponf́veis para o monitoramento e o controle de pragas de graos armazenados: isomeros de trogodermal (genero Trogodexma);isomeros do acido megatombico (genero Attagenus); dominicalure (Rhyzopertha domtnica; Prostephanus trmoatas); 4,8-dimetildecanal (genero Triboliwn); sitophilure (genero sitophilus); TDA (Tetradecadien acetato) (Cadra cantella; Plodia Intexpunotella; outras mariposas); serricornin (Lasiodema serrioorne). 

TABELA 1. Componentes principais de feromónios de coleópteros de grãos armazenados, citados por BURKHOLDER \& MA, 1985.

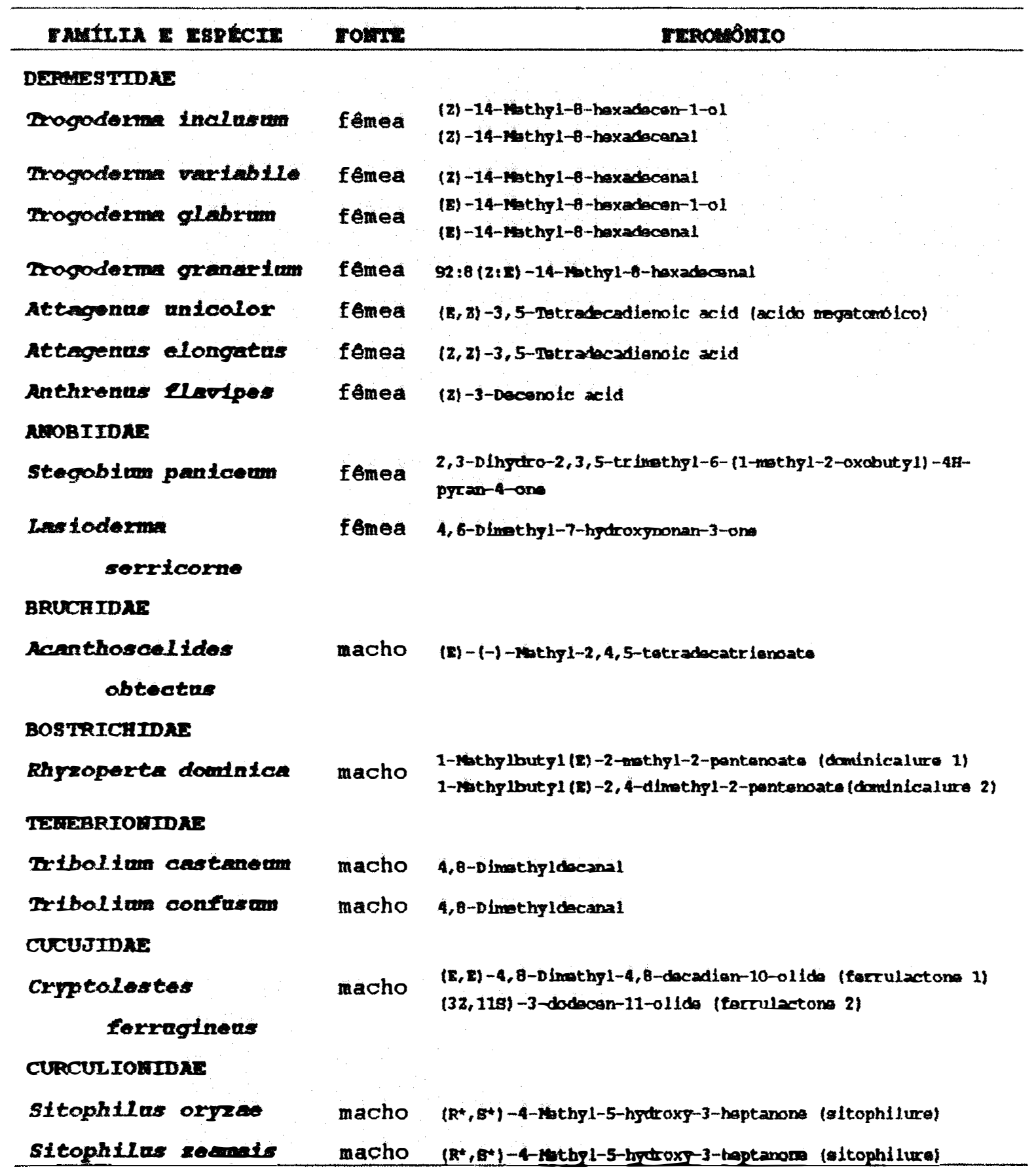


$\mathrm{Na}$ TABELA 2, estão relacionados alguns coleópteros pragas de grăos armazenados cujos feromonios foram identificados mais recentemente, em funçăo do grande número de pesquisas que vem sendo realizado nesta área, pelo seu potencial de aplicação prática.

No Brasil, SILVEIRA NETO \& NAKANO (1984) . estudaram a atratividade do feromonio de $\mathbf{L}$. serricorne e FAVERO et al. (1993) avaliaram a resposta olfativa de $\boldsymbol{s}$. zeamais a seu feromonio sintetico de agregaçăo.

Segundo BURKHOLDER (1982), os insetos de graos armazenados apresentam dois tipos de estrategia reprodutiva e de comunicaçáo. Espécies com adultos de vida curta $<1$ mes), que năo necessitam de alimentaçăo para reproduzir, como mariposas, dermestideos, bruchideos e anobildeos, utilizam feromonios sexuais para comunicaçăo, que săo geralmente produzidos pelas femeas. Especies com adultos de vida longa (> 1 mes) que necessitam alimentaçao para reproduzir, como curculionideos, tenebrionideos, cucujídeos, geralmente usam feromonios de agregaçăo produzidos pelos machos para comunicação, e tanto machos como femeas respondem a esses feromonios.

Feromonios de pragas de grăos armazenados tem sido utilizados de forma promissora no seu monitoramento e controle. TREMATERRA (1989) revisou a utilizaçao de feromônios de pragas de graos armazenados, citando os 


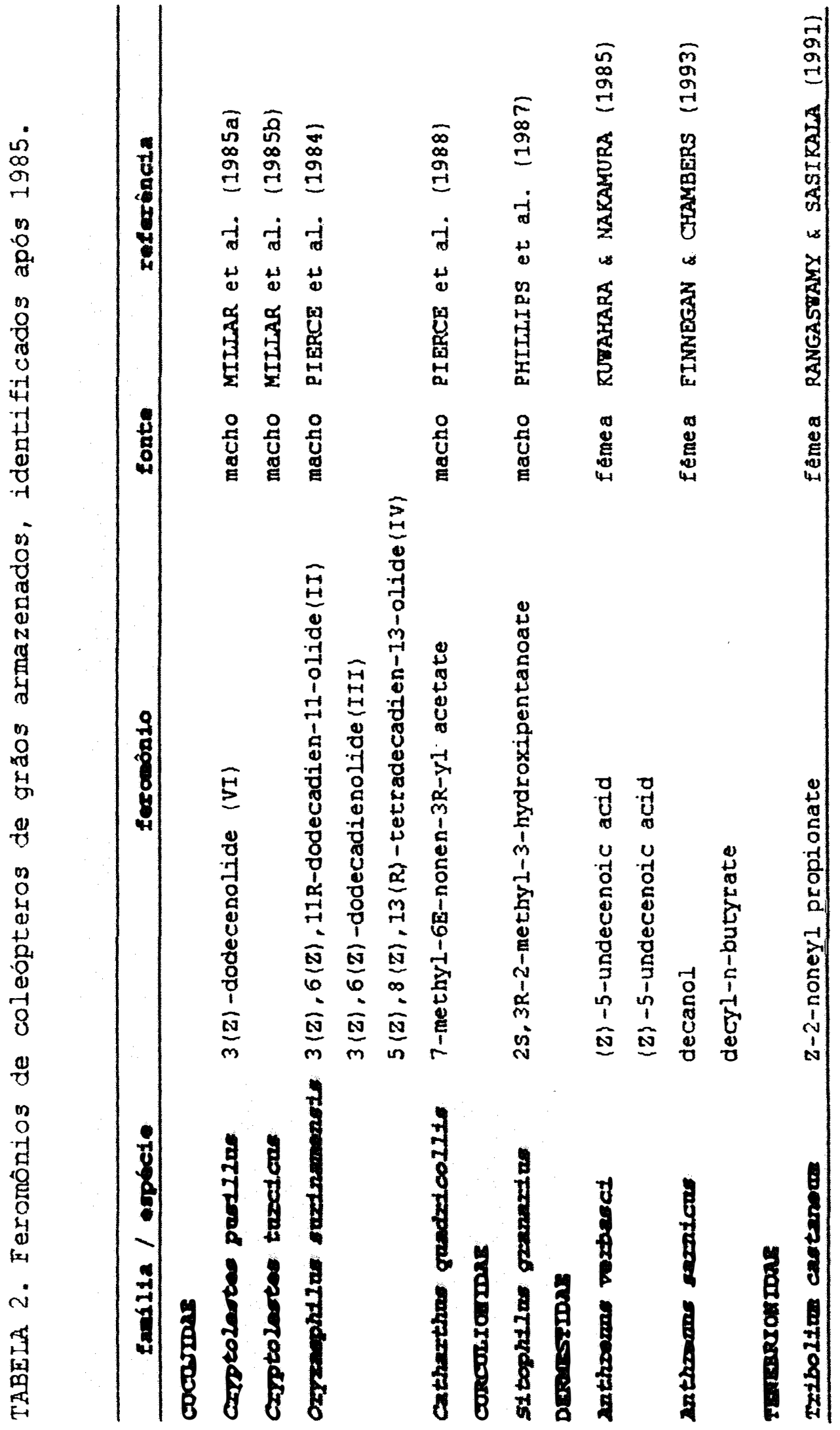


principais trabalhos desenvolvidos na área, visando principalmente o monitoramento populacional, a coleta massal e a supressáo de acasalamentos. Esse autor revisou ainda os principais tipos de armadilha disponiveis para a captura de insetos de gráos armazenados.

CHAMBERS (1990) também revisou a utilizaçåo de feromonios no monitoramento e controle de pragas dos grăos armazenados, citando inúmeros casos de aplicaçăo bem sucedida de feromônios, e também de sua associaçăo com atraentes alimentares, que podem atuar como sinergistas, aumentando bastante o poder de captura.

MUELLER et al. (1990) informam que os feromonios têm sido bastante usados em armazéns, indústrias de alimentos, produtores de sementes e empresas de controle de pragas. No período de 1987-1988, os feromonios mais comercializados foram os de $\boldsymbol{L}$. serrtoome $(48,8), \boldsymbol{P}$. interpunctella $(20,31)$, Trogoderma spp $(14,31)$ e Tribolimn Spp $(5,38)$.

Segundo ARSURA \& ACCINELLI (1990), O monitoramento de populaçóes com o uso de armadilhas, tem possibilitado a reduçăo do número de aplicaçőes de agroquímicos; os autores listaram os 78 tipos de feromonios até entáo disponíveis e as espécies atraídas, entre elas seis pragas de grăos armazenados. 
Segundo CHAMBERS (1990), para a exploração completa do potencial de feromonios e atraentes alimentares, ainda sao necessários estudos em praticamente todas as áreas, desde o desenvolvimento de bioensaios que permitam testar componentes individuais de feromonios em cada comportamento isolado apresentado pelo inseto quando se aproxima de uma armadilha, ate o estudo do modo de ação dos feromonios, que pode indicar formas de interromper a comunicaçåo, como forma de controle.

Recentemente, SINGH (1993) relatou a ocorrencia de feromónios de agregaçăo em machos de A. fasciculatas, e sexuais em femeas da especie, que segundo o autor "induziu o comportamento copulatorio em machos".

\subsection{Bioensaios no estudo do feromônios de insetos}

Segundo BAKER \& CARDE (1984), estudos de comportamento sao essenciais para provar a atividade dos compostos, e o tipo de resposta dos insetos testados pode ser usado para a determinaçăo da função do feromonio (alarme, agregação, sexual, etc.). Os primeiros passos em um estudo de feromónios de uma determinada especie referemse a detecçáo experimental da ocorrencia dos mesmos, identificação dos sexos que liberam essas substancias, determinaçóes da funçăo dos feromónios e das condiçóes 
fisiológicas e ambientais em que ocorrem a liberaçåo e a atraço.

os bioensaios nåo precisam ser caros ou tecnologicamente complexos, porem devem ser conduzidos de forma a aproveitar os mecanismos de resposta usados pelos individuos na recepçåo de mensagens químicas. Eles devem ser desenvolvidos ou adaptados para cada caso, de forma a permitir respostas rápidas e eficientes às situaçoses testadas (BAKER \& CARDÉ, 1984).

Os bioensaios podem avaliar reaçőes diretas ou indiretas a gradientes de concentraçăo, e também considerar o comportamento global do inseto ou apenas alguns aspectos do mesmo. Geralmente, bioensaios que medem o comportamento global e nå se restringem a uma ou duas atividades do comportamento sâo mais discriminatorios (BAKER \& CARDÉ, $1984)$.

No planejamento de um bioensaio, devem ser considerados todos os fatores que influenciam o tipo de informaçåo obtida. Isto inclui o tipo de equipamento onde os insetos sâo observados, a forma de obter respostas reprodutiveis, o número de insetos avaliado (em grupos ou individualmente), a forma de liberaçăo do feromônio, a extensåo do estímulo, o tipo de comportamento a ser observado, e a melhor forma de registrar essas respostas (BAKER \& CARDÉ, 1984). 


\subsubsection{Influênoia de fatores ambientais}

Os fatores ambientais tem grande influencia no estudo de feromonios. Segundo SHOREY (1976), o sexo que libera o feromónio tem a tendencia de produzi-lo sob certas condiçoes favoráveis, e os sexos que recebem o estímulo geralmente tem a tendencia de responder melhor sob as mesmas condiçסes.

\section{Temperatura}

A temperatura pode impor limites superiores e inferiores a resposta e à emissão de feromonios (SHOREY, 1976). Geralmente, a temperatura em que os insetos apresentam maior atividade e melhor desenvolvimento, é utilizada para estudos de comportamento. Segundo PAIVA \& PEDROSA-MACEDO (1985), em escolitídeos, a maior atividade é obtida entre 18 e $23^{\circ} \mathrm{C}$, e por isso o voo destes insetos na primavera registra-se por volta do meio dia, enquanto no veråo o maior número de insetos é capturado de manha e à tarde.

PENA et al. (1992) em bioensaios com Phloeotribas scarabaeoides (Coleoptera: Scolitidae), um escolitideo praga de oliveiras, verificou que a melhor resposta a feromonios foi a $20^{\circ} \mathrm{C}$, sendo as femeas mais sensiveis à variaçăo de temperatura. 
Unidade relativa do ar

A umidade relativa, alem de afetar o comportamento dos insetos, segundo PAIVA \& PEDROSA-MACEDO (1985), influi na sua capacidade de percepçáo do estímulo olfativo. E de se esperar que insetos cujo desenvolvimento e muito afetado pela umidade, como o caruncho-do-cafe, tambem tenham seu comportamento alterado pelas condiçôes de umidade .

\section{Intensidade luminosa}

A intensidade de luz tambem exerce grande influencia na atividade dos insetos, e consequentemente nas respostas a bioensaios. PENA et al. (1992) verificaram que P. soarabaeoldes responde melhor a feromónios em intensidades entre 1000 e 1500 lux. PHILLIPS \& BURKHOLDER (1981), conduziram bioensaios com $\boldsymbol{s}$. oxyzae no escuro, considerando que o ambiente natural desses insetos é escuro ou com muito pouca luz. o mesmo deve ser válido para a. maioria das pragas de grăos armazenados.

\section{Velooidade do ar}

A velocidade do ar e um fator fundamental, em bioensaios com corrente de ar, como túneis de vento, usados principalmente com lepidópteros, em que a velocidade 
excessiva pode inibir o voo, enquanto a velocidade muito baixa pode impedir a orientaçao do inseto em relaçáo à fonte emissora do feromónio.

\section{Fotofase}

As condiçoes fisiológicas do inseto controlam o seu comportamento, e em interaçăo com as condiçóes ambientais, determinam quando onde e como a comunicaço química ocorrerá.

A maioria dos comportamentos dos insetos såo exibidos somente durante horarios especificos de cada dia. Esses rítmos diários de comportamento (rítmos circadianos) săo frequentemente controlados por processos endógenos, que săo sincronizados com o horário atraves da percepço pelo inseto das alteraçóes diárias do ambiente, como luz e escuridåo.

A Eotofase influencia o ritmo de produço e resposta a feromónios, embora este seja um aspecto pouco estudado em pragas de grăos armazenados. HAMMACK \& BURKHOLDER (1976) estudaram o efeito de variaçoes na fotofase em Trogoderna glabrom e verificaram que o pico de emissăo e resposta a feromónios, à medida que aumenta a fotofase, vai ocorrendo a intervalos maiores em relaça ao 
seu inicio, mantendo-se em torno de uma hora após a metade da fotofase.

A hora do dia é considerada na maioria dos bioensaios com pragas dos grăos armazenados, por determinar o horário em que os insetos estão mais ativos, respondendo melhor aos estímulos olfativos. HAMMACK et al. (1976) verificaram que o comportamento de chamada e a produçáo de feromonios em T. glabrem em uma fotofase de 16 horas, concentrava-se em um período de oito horas, localizado no meio do período de luz. PHILLIPS \& BURKHOLDER (1981) observaram que a maior atividade de $\boldsymbol{s}$. oryzae ocorreu entre 11 e 15 horas, com uma fotofase de 16 horas.

OBENG-OFORI \& COAKER (1990) avaliaram a resposta de quatro especies, T. castanewn, T. confurwn, Prostephanks trumcatas (Coleoptera: Bostrichidae) e $\boldsymbol{R}$. dominiaa, em diferentes horários. $\mathbf{R}$. dominiaa e $\boldsymbol{P}$. truncatas atingiram um pico de resposta acima de 60 entre 14 e 15 horas, e um minimo de 27-308 entre 21 e 1 hora, para os dois sexos. Em T. castanewn, machos atingiram pico de 678 e fomeas de 578, entre 13 e 14 horas, declinando ate 30-338 as 22-23 horas. Machos e fêmeas de $\boldsymbol{r}$. amsom atingiram picos de 60 e 638 entre 12 e 13 horas, e um minimo de 30-33 entre 23 e 24 horas.

EINNEGAM \& CHAMBERS (1993) coletaram o feromônio de A. sacnicus entre 13:30 e 15 horas, por ser o período em 
que o maior número de femeas apresenta comportamento de chamada.

\subsubsection{Influênoia de fatores biológioos}

\section{Idade}

A idade em que os insetos atingem a maturidade sexual é geralmente aquela em que se inicia a produçåo e a resposta a feromonios. HAMMACK et al. (1976) utilizaram adultos de 6 a 12 dias de idade, na avaliaçăo da liberaçåo de feromónios em femeas de $\boldsymbol{T}$. glabrum. BORDEN et al. (1979) verificaram que em $\boldsymbol{C}$. ferrogloens, adultos de 4-6 meses nao respondiam a feromonios, mas atralam besouros de 3-20 dias. Esses autores utilizaram insetos com menos de 3 meses para a determinaçao de feromonios na especie.

PHILLIPS \& BURKHOLDER (1981) utilizaram insetos de 6-7 dias na determinaçăo do feromonio de agregaçáo de $s$. oryzae. Para essa especie, WALGENBACH \& BURKHOLDER (1986) verificaram que o máximo de resposta foi obtido com adultos de até uma semana de idade, a partir da qual a resposta diminuia significativamente. OBENG-OFORI \& COAKER (1990) verificaram que adultos de $\boldsymbol{T}$. castanewn e $\mathbf{T}$. confusun responderam significativamente a feromonios entre 1 e 21 dias, e o aumento da idade teve um efeito significativo na 
resposta. Em T. astanem 40 dos machos de 1 a 3 dias responderam ao estimulo, e 63 aos 19 dias; 30 das femeas responderam aos $1-3$ dias e 508 aos 21 dias. Em T. canfuswn - comportamento dos machos foi semelhante, enquanto as femeas apresentaram o máximo de 608 de respostas aos 16 dias, caindo para 348 aos 21 dias.

\section{sexo}

o sexo é uma condiçåo que obviamente interfere na produçăo e resposta a feromônios. Embora em muitas espécies os dois sexos os produzam, cada sexo produz um feromónio especifico, e os sexos que respondem dependem do tipo de feromônio, se de agregaçåo ou sexual.

\section{Acasalamento}

A condição de acasalado tambem pode influenciar a . produçåo de feromónios, especialmente os sexuais. No caso de feromónios de agregação, PHILLIPS \& BURKHOLDER (1981) verificaram que machos e femeas de $\boldsymbol{s}$. oryzae acasalados responderam ao feromónio de machos, porem machos acasalados atraíram um número menor de machos e femeas virgens, mas ainda em níveis significativos. OBENG-OFORI \& COAKER (1990) nåo observaram diferenças nas respostas de adultos 
acasalados de $\boldsymbol{T}$. castanewn, $\boldsymbol{T}$. confusum, $\boldsymbol{P}$. trumcatus $\mathbf{R}$. dontrica.

\section{Habituação}

Habituaçá é definida como um decréscimo gradual na intensidade de resposta a um estímulo repetido. OBENGOFORI \& COAKER (1990) verificaram que a exposiço a feromónios por 2 a 8 horas reduziu a resposta de $T$. castanewn, r. comfusm a feromónios, entretanto a capacidade de resposta foi recuperada 48 horas depois, exceto para machos de T. anfurm .

\section{Alimentação}

A falta de alimentaçáo pode alterar o nivel de resposta, especialmente em feromónios de agregaço. WALGENBACH \& BURKHOLDER (1986) avaliaram o efeito da falta de alimento na resposta de s. zeamats a sitophinone, e verificaram um aumento na mesma em períodos de ate 12 horas sem alimentação. Períodos maiores levaram a uma diminuiçăo da resposta, enquanto a atividade dos insetos aumentou de forma significativa ate o maior periodo sem alimento, de 48 horas. 


\section{Densidade populaoional}

A resposta pode ainda ser influenciada pela populaçåo de insetos, ocorrendo em altas densidades populacionais uma maior tendencia a procura de novas fontes de alimento. WALGENBACH \& BURKHOLDER (1986) avaliaram O efeito de populaçőes de $s$. zeamats de 0,$1 ; 0,4 ; 1,0$ e 10 insetos por $\mathrm{ml}$ de trigo, com idades de $1-2$ dias e 10 semanas. Observaram que nos insetos mais novos, em populaçóes de 0,4-10 adultos por $\mathrm{ml}$ de trigo, houve um aumento significativo na resposta a feromónios, ao contrário do ocorrido com insetos com 10 semanas. A atividade aumentou com a densidade nas duas idades, porem de forma mais significativa nos insetos de 10 semanas. PIERCE et al. (1983), ao contrário, encontraram respostas menores com o aumento da densidade de 0 . sarnamensis, que em altas densidades chegaram ate a ser repelidos pelos voláteis de insetos. Neste caso a capacidade de resposta foi recuperada quando os insetos foram transferidos para um meio novo, com baixa densidade populacional.

Todos esses aspectos mostram o nível de detalhes necessário na condução e interpretaçăo de bioensaios de comportamento de insetos em laboratorio. As flutuaçoes de resposta sao a regra, e o bioensaio deve ser otimizado para - período em que o inseto demonstra resposta mais intensa ao estímulo (BAKER \& CARDE, 1984). 


\subsubsection{Tipos de olfatometros}

Os bioensaios para estudo do comportamento de insetos a estímulos olfativos săo desenvolvidos geralmente em olfatómetros, que podem ser de diversos tipos e devem ser adaptados ou desenvolvidos para cada caso, de forma a permitir respostas rápidas e eficientes às situaçóes testadas.

BAKER \& CARDE (1984) revisaram as técnicas de bioensaios para estudo de comportamento, examinando inúmeros tipos de aparelhos utilizados em pesquisas de feromónios, classificando-os em quatro categorias:

sem corrente de ar:

- Com deslocamento dos insetos em relação a fonte;

- Sem deslocamento dos insetos em relaçáo a fonte;

Com corrente de ar:

. Com deslocamento dos insetos em relaçăo à fonte:

. Sem deslocamento dos insetos em relaçăo à fonte.

Os olfatometros em que năo há deslocamento dos insetos em relaçăo a fonte de atraçăo săo pouco utilizados com pragas de grăos armazenados. VICK et al. (1970) testaram a resposta de dermestideos (Trogoderna spp) a feromónios, usando um olfatometro desse tipo, sem corrente de ar. Cada inseto era mantido em um frasco de vidro de $3,7 \mathrm{ml}$ (1 dram) por uma hora, e entăo era introduzido um disco de papel com o extrato equivalente a 0,01 femea, 
sendo registrado o comportamento do inseto, principalmente movimentos de antenas e pernas dianteiras, e movimentos em círculos.

Os olfatómetros em que há deslocamento do inseto em relaçăo a fonte săo mais comuns. BURKHOLDER \& DICKE (1966) detectaram a ocorrencia de feromonios em fêmeas de Attagenas piceas, T. tnclaswn e T. glabrom, utilizando um olfatometro com tres opçós de escolha, sem corrente de ar, constituido de um dessecador, dentro do qual encontrava-se a arena, de papel de filtro. Os insetos eram liberados no centro e atraidos para tres discos de papel que ficavam suspensos sobre a arena, contendo as substancias atraentes. Este mesmo tipo de olfatometro foi utilizado por COFFELT \& BURKHOLDER (1972), estudando o feromonio de femeas de $L$. serricorae.

BORDEN et al. (1979) utilizaram um olfatometro com corrente de ar e deslocamento dos insetos em relaçăo a uma única fonte, em uma arena aberta de 7,5 x 7,5 cm, na determinaçăo do feromonio de agregaçăo produzido por machos de c. ferragineas. Os insetos eram liberados do lado oposto ao ponto onde sala uma corrente de ar arrastando os voláteis, que os atralam.

Para a avaliaçăo do comportamento de $\boldsymbol{s}$. oryzae ao seu feromónio de agregaçăo, PHILLIPS \& BURKHOLDER (1981) utilizaram um olfatometro de duas escolhas, sem corrente de 
ar, no qual uma placa de cristalizaçăo $180 \mathrm{~mm}$ de diametro $\mathrm{x}$ $50 \mathrm{~mm}$ de altural foi usada como camara, cobrindo uma arena de vidro com dois furos, com frascos de vidro como alçapóes para onde foram atraidos os insetos.

OBENG-OFORI COAKER (1990) utilizaram um olfatômetro com uma câmara única de $60 \mathrm{~cm}$ de comprimento $\mathrm{x}$ $20 \mathrm{~cm}$ de largura $\times 2 \mathrm{~cm}$ de altura, com corrente de ar, que arrastava os voláteis, atraindo os insetos para a sua fonte de origem, na avaliaçăo de respostas a feromónios de $T$. castanewn, T. confurwn, R. domintica e P. truncatas.

FINNEGAN \& CHAMBERS (1993) utilizaram um olfatometro de duas escolhas, sem corrente de ar, consistindo de uma arena de papel de filtro, limitada por um anel de alumínio de $10 \mathrm{~cm}$ de diametro, coberto por uma placa de petri de $12 \mathrm{~cm}$ de diametro. Na arena eram colocados adultos de A. samfors e dois discos de papel de filtro de $2 \mathrm{~cm}$ de diametro, impregnados com voláteis de fomeas da espécie, que atraíam os machos.

CHAMBERS et al. (1990) testaram o comportamento de $C$. ferrugineas e c. pasillas em relaçăo a componentes do feromónio sintético de agregação da espécie, utilizando um bioensaio sem corrente de ar com duas escolhas, com alçapóes, utilizando como câmara uma placa de Petri de $10 \mathrm{~cm}$ de diametro. 
Verifica-se que os olfatometros sem corrente de ar såo pequenos, e os insetos såo liberados próximos da fonte de atraça, pois nesse caso a difusao dos volatels e lenta. 


\section{MATERTAL E MÉtOdOS}

\subsection{Criação de $\mathbf{A}$. fascioulatus}

Os carunchos, obtidos em criaçåo mantida no Instituto Biológico, em Săo Paulo, SP, a partir de insetos coletados em armazéns de café em Santos, SP, foram criados em sala especialmente adaptada, na seça de pragas das Plantas Industriais do Instituto Biológico, em Campinas, $S P$, com temperatura de $27 \pm 2^{\circ} \mathrm{C}$, mantida por aparelho de ar condicionado, fotof ase de 12 horas e umidade relativa do ar de $90 \pm 5 \%$, condiçoes adequadas ao desenvolvimento dos insetos.

A umidade relativa do ar foi mantida em níveis elevados, $90 \pm 58$, através de um sistema de umidificaçăo (FIGURA 1) desenvolvido e instalado na sala de criaçăo, constituído de uma camara de ebuliçăo, formada por um tubo de cimento amianto de $9 \mathrm{~cm}$ de diametro por $30 \mathrm{~cm}$ de comprimento, fechado em uma das extremidades e com uma resistencia (2000 W, 220 V) adaptada na outra. Sobre esta camara foram colocados dois tubos do mesmo material, de 6 
nesta camara por um tubo de ferro de $2 \mathrm{~cm}$ de diametro por $33 \mathrm{~cm}$ de comprimento, acoplado por um tubo plástico flexível a uma caixa d'água de 20 litros, equipada com bóia, que permitia regular o nivel de agua na camara de ebuliçăo. A resistencia foi ligada a rede eletrica atraves de um umidistato, que controlava a produça de vapor d'água.

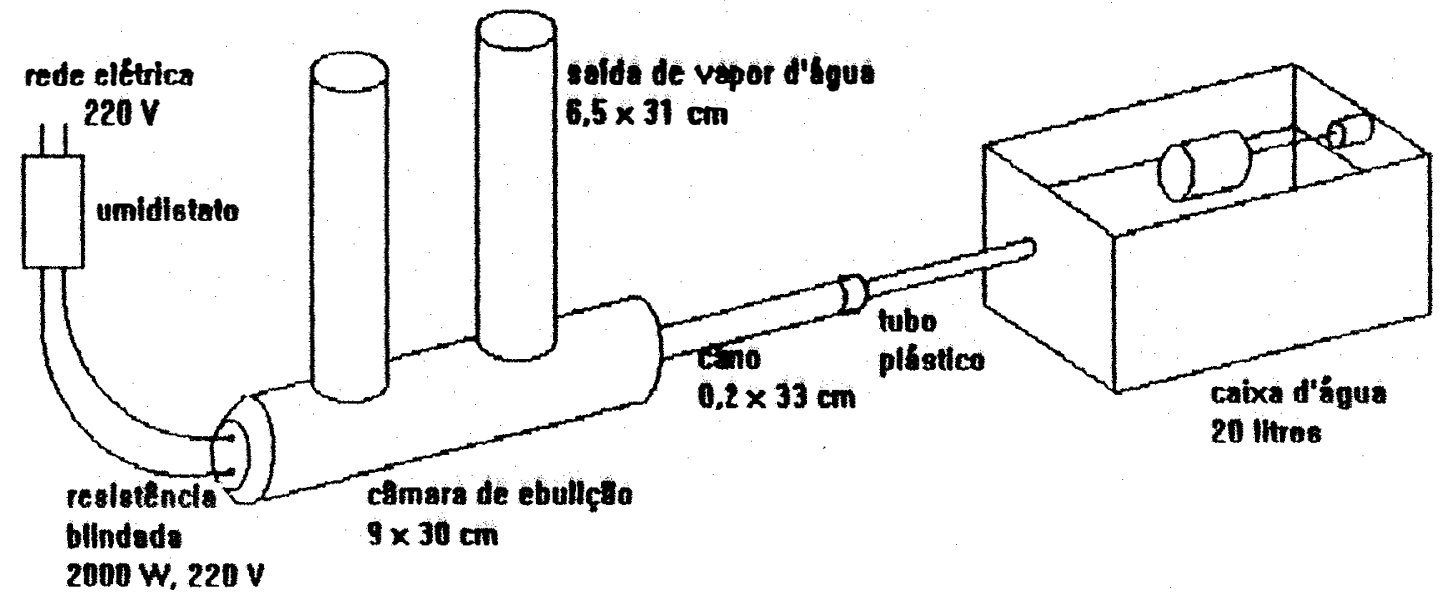

FIGURA 1. Sistema de umidificação utilizado na criaçăo de A. fascionlatus (A figura năo está em escala. Observar as dimensoes indicadas). 
Os insetos foram mantidos em frascos de vidro de $500 \mathrm{ml}$ com tampa telada, contendo $200 \mathrm{~g}$ de grăos de café da variedade Mundo Novo, com umidade corrigida para 128, que recebiam no inj́cio uma infestaçăo de 150-200 adultos de 1-2 semanas de idade. Para a obtençăo do alto número de insetos necessário para os bioensaios, foram preparados dois frascos de críaçăo a cada semana. Em cada frasco de criaçăo, foi colocado um tubo de vidro de $6 \mathrm{~mm}$ de diametro x $25 \mathrm{~mm}$ de altura, contendo algodáo umidecido como fonte de umidade adicional, que segundo PUZZI \& PEREIRA (1967), favorece o desenvolvimento do inseto.

\subsection{Cialo de vida}

o ciclo de vida, de ovo a adulto, foi determinado, colocando-se 100 adultos em $20 \mathrm{~g}$ de grăos năo infestados, por 24 horas, após o que os adultos eram retirados, sendo os grăos observados diariamente para anotaçăo dos adultos emergidos. Essas observaçóes foram mantidas até ocorrer um período de 15 dias sem nenhuma emergencia, quando considerou-se que todos adultos haviam emergido. Foram feitas 6 repetiçoes do experimento, determinando-se a duraçăo média e a intervalo de variaçăo do ciclo, informaçăo utilizada nas fases seguintes do trabalho. 


\subsection{Preparạ̧ão e realizạ̧ão dos bloensalos}

\subsubsection{Sexagem manutenção dos adultos}

Os adultos recem emergidos foram obtidos pelo peneiramento diário dos frascos de criaçăo que contavam entre 60 e 120 dias de infestaçăo, período em que havia maior emergencia.

o peneiramento foi realizado utilizando-se um conjunto de tres peneiras e fundo, com a seguinte disposiça: em cima, peneira de abertura 0,42 mm (Tyler 35), para impedir a salda dos insetos, a seguir peneiras de aberturas de $2,0 \mathrm{~mm}$ (Tyler 9), que retem os grăos de cafe e de $0,84 \mathrm{~mm}$ (Tyler 20), que retém os insetos, e o fundo, que retém o pó.

Os insetos foram anestesiados com $\mathrm{CO}_{2}$, em um frasco de vidro de $500 \mathrm{ml}$, com um fluxo de $350 \mathrm{ml} / \mathrm{mim}$ de gás, determinado através de um fluximetro de bolha. Os insetos anestesiados foram separados de acordo com o sexo, atraves das caracteristicas morfológicas descritas por EL SAYED (1940) (FIGURA 2). 
Q
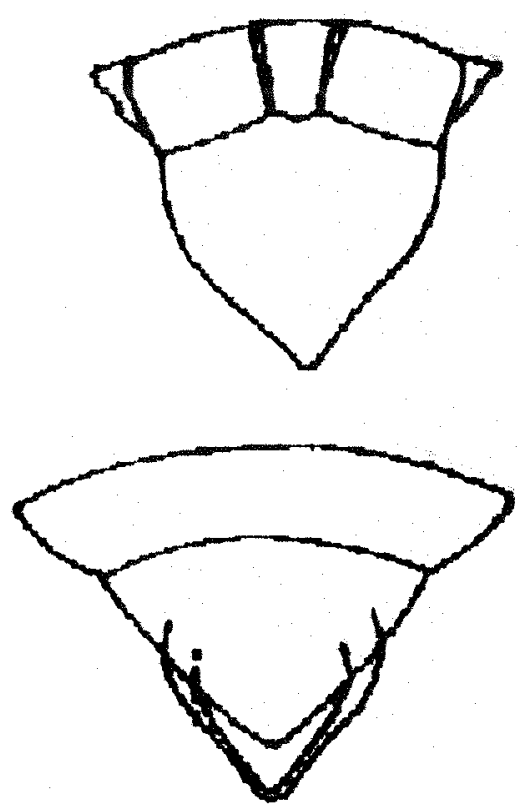

VENTRU

Doresal
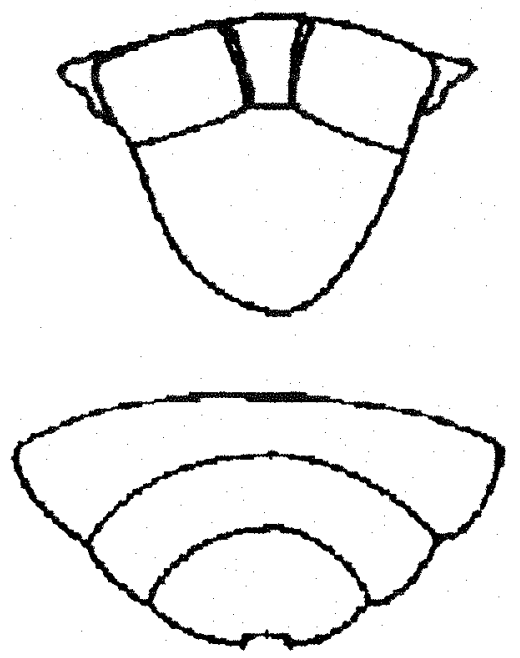

LATERAL

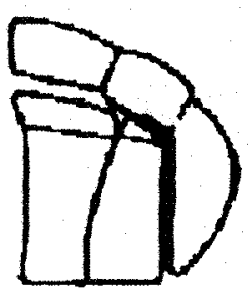

FIGURA 2. Diferenciaçăo de sexos de A. Lasotanlatas por caracteristicas morfologicas da regiao posterior do abdome de adultos (EL SAYED, 1940).

A separaçåo foi feita em microscópio binocular, cuja mesa foi substituida por um conjunto de aluminio com dois furos de $6 \mathrm{~mm}$ de diametro, sob os quais ficavam presos tubos de vidro de $15 \mathrm{~mm}$ de diametro $\times 60 \mathrm{~mm}$ de altura, fechados por funis de vidro de mesmo diametro dos tubos, 
que tinham o terço superior interno coberto por uma fina camada de fluon (EIGURA 3). Assim, os insetos eram sexados e com um pincel empurrados para um dos alçaposes, conforme o sexo, ficando presos nos tubos de vidro. Esse procedimento permitiu a separaça do grande número de insetos necessário, sem danificá-10s. Durante a sexagem, os insetos lesionados no peneiramento, e aqueles em que havia dúvidas quanto ao sexo, eram eliminados.

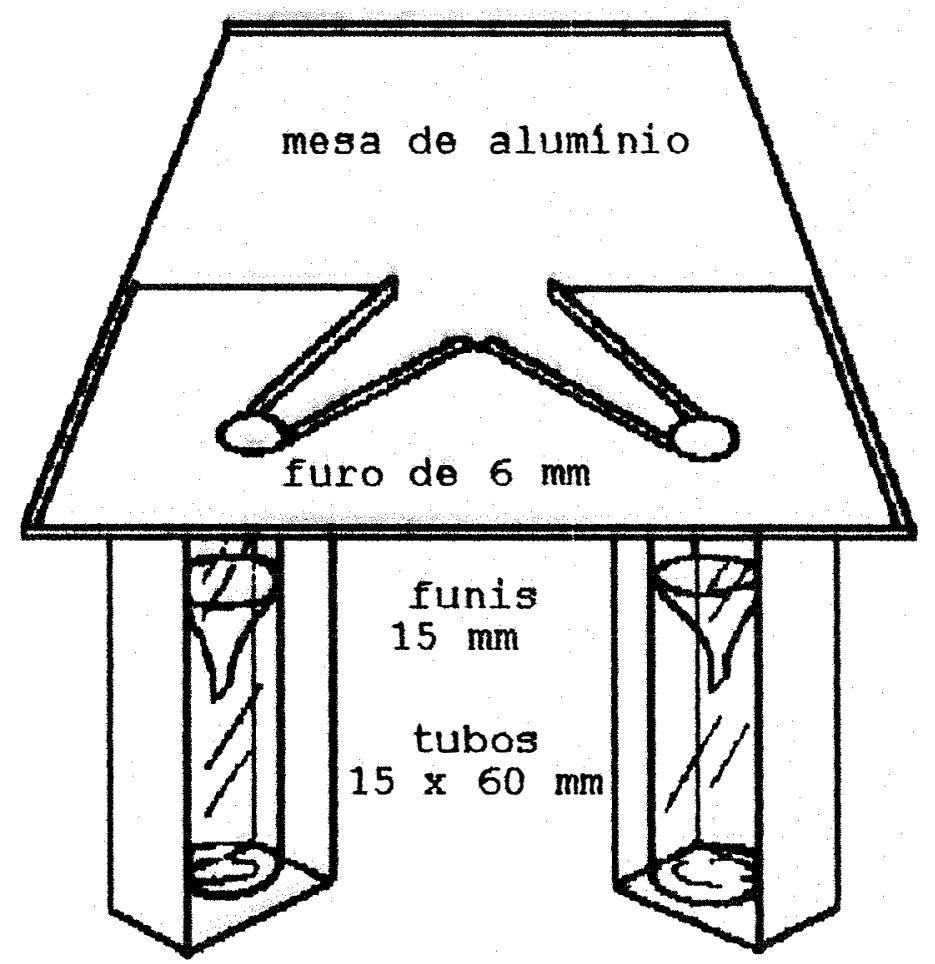

FIGURA 3. Mesa de microscópio binocular utilizada para a sexagem de A. Iasolonlatos. 
Os insetos de cada sexo foram mantidos em tubos de vidro de $30 \mathrm{~mm}$ de diametro x $160 \mathrm{~mm}$ de altura, contendo cerca de $20 \mathrm{~g}$ de café, e um tubo de $6 \times 25 \mathrm{~mm}$, contendo algodao umidecido com água e tampados com uma placa de Petri de $40 \mathrm{~mm}$ de diametro $\times 15 \mathrm{~mm}$ de altura. Em cada tubo foram colocados cerca de 70 insetos, resultando uma infestaçăo de 3,5 insetos/g de graos. Esses tubos foram mantidos em camaras de temperatura controlada separadas, para evitar o condicionamento aos voláteis do sexo oposto. As condiçós de temperatura e umidade relativa do ar foram iguais as da sala de criaçăo, em todos os testes realizados.

\subsubsection{Determinap̧ão da ldade de acasalamento}

Foram testados insetos de 1 ate 10 dias de idade, em todas as 100 combinaçőes possíveis de machos e fémeas, sendo observados 10 casais em cada uma. As observaçóes foram realizadas entre 9 e 11 horas, em sala isolada da sala de criaçăo. Cada casal foi colocado em frasco de vidro de $5 \mathrm{ml}$ de capacidade, e durante uma hora o seu comportamento foi avaliado, principalmente quanto a ocorrencia de cópula.

A cada teste, a sala era ventilada por 4 horas e a vidraria lavada com detergente alcalino, enxaguada com água e álcool etilico absoluto, e seca em estufa a $110^{\circ} \mathrm{C}$. $\mathrm{O}$ total de machos e femeas de cada idade, que copularam, foi 
submetido a análise de variancia, sendo as médias comparadas pelo teste de Duncan a 5 de probabilidade.

\subsubsection{Bioensalos para avaliạ̧ão de feromônios}

Em estudos preliminares, foram avaliadas diversas substancias que poderiam atuar como absorvente do material atrativo, como papel de filtro, algodåo e discos de ensaio bacteriano, altamente absorventes $\left(\mathrm{n}^{\circ}\right.$ 740-E, Carl Schleicher and Co., Keene, N.H., USA), entretanto só houve respostas consistentes quando foram usados adultos vivos como fonte de atraçåo.

Esses adultos, virgens, foram mantidos em tubos de vidro de $6 \mathrm{~mm}$ de diametro x $25 \mathrm{~mm}$ de altura, por perlodos variaveis, de 1 a 10 dias, a partir do dia da emergencia. Em cada tubo foi colocada ainda, uma camada de $3 \mathrm{~mm}$ de algodao hidrofilo, préviamente mantido em ambiente saturado de umidade por 24 horas, e um grao de cafe beneficiado. Para cada tubo com adulto foi tambem preparado um tubo contendo somente o algodao e o grao de café, usado como testemunha. Estes tubos, fechados com filme de PVC, foram mantidos em camara de temperatura controlada em sala separada, pelas razoes já expostas.

o olfatometro utilizado, com dois alcapóes, foi modificado daquele proposto por PHILLIPS \& BURKHOLDER 
(1981), sem corrente de ar forçada e com deslocamento dos insetos em relação a fonte de atraçao (FIGURA 4). Consistiu de uma camara, formada por uma placa de cristalização de $90 \mathrm{~mm}$ de diametro $\times 50 \mathrm{~mm}$ de altura, mantida invertida sobre uma base de plástico (arena) de $95 \mathrm{~mm}$ de diametro, com uma pequena saliencia ao longo da borda, permitindo o encaixe da placa. Na arena haviam dois furos de $20 \mathrm{~mm}$ de diametro, em posiçoes opostas, distantes entre si $30 \mathrm{~mm}$, e a $15 \mathrm{~mm}$ do centro da arena. No centro da arena foi colocada uma placa de vidro, invertida, de $20 \mathrm{~mm}$ de diametro x $15 \mathrm{~mm}$ de altura, que podia ser elevada através de uma haste metálica de $1 \mathrm{~mm}$ de diametro que atravessava o centro da arena. A arena foi mantida sobre dois tubos de vidro (alcapoes) de $20 \mathrm{~mm}$ de diametro $\times 50 \mathrm{~mm}$ de altura, encaixados nos furos.

Antes de cada teste todo material foi lavado com detergente alcalino, enxaguado com água e álcool etílico absoluto, e seco em estufa a $110^{\circ} \mathrm{C}$ (vidraria) ou a temperatura ambiente (plástico). Foram aplicadas, uma fina camada de vaselina neutra, internamente na placa de cristalizaçăo, e uma camada de fluon, no terço interno superior dos tubos e em toda a placa de $20 \mathrm{~mm}$ de diametro $\mathrm{x}$ $15 \mathrm{~mm}$ de altura, para forçar os insetos a permanecerem na arena de plástico e impedi-los de escapar dos alcapoes. 


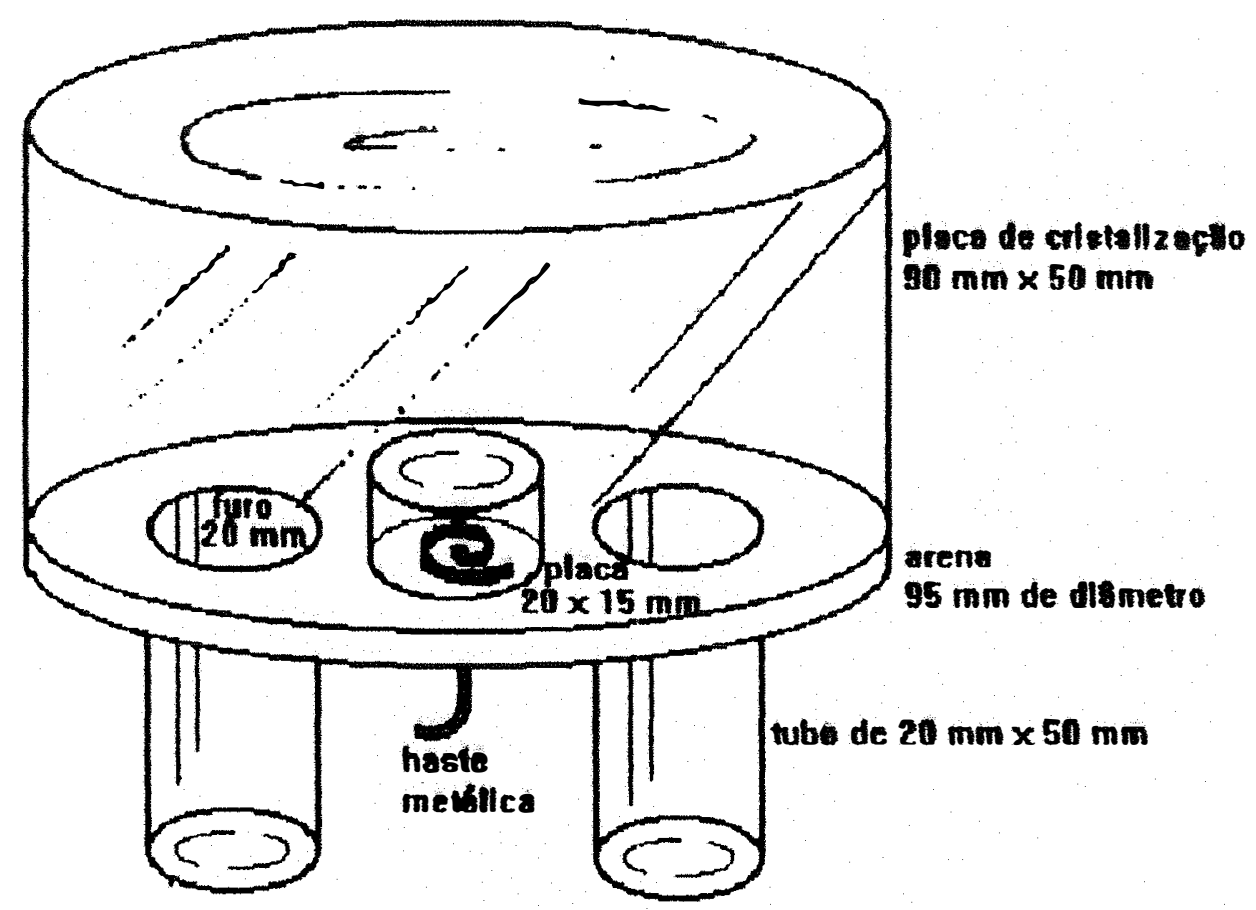

medidas collindricas $=$ diâmetro $\times$ altura

FIGURA 4. Olfatometro utilizado nos bioensaios com A. fascloalatas (A figura náo está em escala. Observar as dimensoes indicadas.).

Para a realizaçâo dos bioensaios, 10 insetos, machos ou femeas, retirados dos tubos de manutençăo eram colocados na placa de $20 \mathrm{~mm}$ de diametro $x 15 \mathrm{~mm}$ de altura, que era entáo colocada no centro da arena. Após um período de condicionamento de 15 minutos, no escuro, a sala era iluminada com uma lampada vermelha de $40 \mathrm{~W}$, e eram 
colocados em um alcapão o tubo contendo o caruncho (material em teste), e no outro o tubo testemunha, sendo a posiçâo de cada um aleatória. Nos dois casos, o filme de PVC era furado 5 vezes com um alfinete entomologico $n^{\circ} 5$, permitindo-se a liberacâo dos odores.

A placa de cristalizaçăo era enta colocada sobre a arena, e a placa de $20 \mathrm{~mm}$ de diametro X $15 \mathrm{~mm}$ de altura era levantada, permitindo-se a livre movimentaçăo dos carunchos. Aposs 40 minutos no escuro, tempo suficiente para os insetos efetuarem a escolha, determinado em testes preliminares, era feita a contagem do número de insetos em cada alcapåo e dos remanescentes na arena.

Foi utilizado um conjunto de 6 olfatometros, permitindo-se a realizaçăo de seis bioensaios simultaneos. Os testes foram realizados em sala utilizada somente para este fim, mantida a $27 \pm 2^{\circ} \mathrm{C}$, e UR de $90 \pm 5$, entre 9 e 11 horas. Os insetos eram utilizados nos bioensaios apenas uma vez.

A atratividade dos voláteis de machos e fémeas foi avaliada em relaçăo a machos e fêmeas virgens, com idades variando de 2 a 10 dias em 38 combinaçóes de idades e sexos (tratamentos), totalizando 380 bioensaios (TABELA 3) . Em cada bioensaio sempre foi utilizada uma testemunha, preparada no mesmo momento que o individuo usado como fonte. As combinaçóes testadas foram determinadas ao longo 
do trabalho, em função dos resultados que iam sendo obtidos.

Cada bioensaio foi repetido 10 vezes, sendo os resultados analisados pelo teste $t$ para dados pareados. Foram considerados significativos os resultados em que $P<0,05$ 
TABELA 3. Idades (dias) e sexos, dos adultos de $\mathbf{A}$. fascioulatus usados como fonte de volateis e como receptores nos bioensaios realizados.

\begin{tabular}{|c|c|c|c|}
\hline FONTE & IDADE & RECEPTORES & IDADE \\
\hline \multirow{6}{*}{ EMEA } & 6 & EEMEAS & 7 \\
\hline & 7 & & 7 \\
\hline & 7 & & 8 \\
\hline & 8 & & 8 \\
\hline & 8 & & 9 \\
\hline & 9 & & 7 \\
\hline \multirow[t]{5}{*}{ FEMEA } & 7 & MACHOS & 7 \\
\hline & 7 & & 8 \\
\hline & 8 & & 8 \\
\hline & 9 & & 8 \\
\hline & 9 & & 9 \\
\hline \multirow[t]{10}{*}{ MACHO } & 5 & MACHOS & 8 \\
\hline & 6 & & 7 \\
\hline & 6 & - & 8 \\
\hline & 7 & & 6 \\
\hline & 7 & & 7 \\
\hline & 7 & & 10 \\
\hline & 8 & & 8 \\
\hline & 8 & $\cdot$ & 9 \\
\hline & 9 & & 8 \\
\hline & 10 & & 8 \\
\hline \multirow[t]{17}{*}{ MACHO } & 2 & FEMEAS & 8 \\
\hline & 3 & & 8 \\
\hline & 4 & & 8 \\
\hline & 5 & & 8 \\
\hline & 6 & & 6 \\
\hline & 6 & & 8 \\
\hline & 7 & & 4 \\
\hline & 7 & & 7 \\
\hline & 7 & & 8 \\
\hline & 8 & & 3 \\
\hline & 8 & & 5 \\
\hline & 8 & & 7 \\
\hline & 8 & & 8 \\
\hline & 8 & & 10 \\
\hline & 9 & & 8 \\
\hline & 9 & & 9 \\
\hline & 10 & & 8 \\
\hline
\end{tabular}




\section{Resurtados e discussão}

\subsection{Cialo de vida de A. Fasoionlatas}

Foram obtidos um total de 96 adultos, com o ciclo de ovo a adulto variando de 57 a 97 dias, com uma média de $72,4 \pm 1,0$ dias, em cafe da variedade Mundo Novo, com umidade corrigida para 128 , temperatura de $27 \pm 2^{\circ} \mathrm{C}$ e umidade relativa do ar de $90 \pm 5$. O intervalo de variaça diferiu daquele obtido por AUTUORI (1931) de 47-63 dias e dos obtidos por GONÇALVES et al. (1976), de 53-75 dias em temperatura de $21-24^{\circ} \mathrm{C}$ e de $44-56$ dias em temperatura de $25-29^{\circ} \mathrm{C}$. Foi semelhante ao obtidos por CABAL CONCHA (1956), 56-81 dias a $28^{\circ} \mathrm{C}$ e 80 UR e por LAVABRE \& DECAzY (1968), de $65-90$ dias a $25^{\circ} \mathrm{C}$ e 80 UR.

o caruncho-do-café é um inseto muito sensível a umidade e por isto, o seu teor nos gras certamente tem grande influencia no desenvolvimento do inseto. PUZZI \& PEREIRA (1967) verificaram que as infestaçбes ocorrem com maior intensidade em Santos, SP, do que em Săo Paulo, SP, considerando as maiores temperaturas e umidades relativas 
da primeira como os fatores responsáveis. Esses autores ainda citaram que o teor médio de umidade dos gráos de cafe no final do experimento foi 14,78 em sao Paulo e 17,68 em Santos, discutindo a possibilidade de uma "açăo conjunta" da alta umidade relativa e da maior umidade dos gráos, favoravel a infestaçăo.

Os demais autores, apesar de considerarem a umidade relativa do ar muito importante, năo mencionam a umidade dos gráos usados em seus experimentos, tendo-se difundido o conceito de que as infestaçós somente ocorrem com gravidade em locais de umidade relativa alta.

A umidade dos gráos 6 dependente da umidade relativa do ar e certamente ta importante quanto esta no desenvolvimento do caruncho-do-cafe, devendo este aspecto ser citado para permitir comparação mais precisa dos resultados obtidos por diferentes pesquisadores.

\subsection{Idade da ó́pula}

Os machos e fêmeas copularam em todas as idades avaliadas; entretanto machos de 1 e 2 dias somente o fizeram com femeas de 6 ou mais dias, e fêmeas de 1 dia somente copularam com machos de 8 ou mais dias (TABELA 4). Entre adultos de 1 a 5 dias, primeiro acasalamento ocorreu entre macho de 3 dias e femea de 2 dias, coincidindo com a 
observaçao de AUTUORI (1931), que obteve as primeiras cópulas com adultos de 2-3 dias.

TABELA 4. Número de acasalamentos de $\boldsymbol{A}$. fasciculatus em cada combinaçáo de idades, de 1 a 10 dias. (Número de casais observados em cada idade = 10) .

\begin{tabular}{ccccccccccc}
\hline $\begin{array}{c}\text { idade } \\
\text { dos } \\
\text { machos }\end{array}$ & 1 & 2 & 3 & 4 & 5 & 6 & 7 & 8 & 9 & 10 \\
\hline 1 & 0 & 0 & 0 & 0 & 0 & 0 & 0 & 1 & 1 & 0 \\
2 & 0 & 0 & 0 & 0 & 0 & 1 & 1 & 1 & 0 & 0 \\
3 & 0 & 1 & 0 & 1 & 2 & 3 & 1 & 5 & 2 & 1 \\
4 & 0 & 1 & 1 & 1 & 3 & 3 & 1 & 2 & 2 & 3 \\
5 & 0 & 3 & 3 & 5 & 6 & 4 & 3 & 4 & 5 & 4 \\
6 & 0 & 1 & 2 & 5 & 6 & 4 & 4 & 6 & 6 & 4 \\
7 & 0 & 0 & 6 & 6 & 5 & 8 & 8 & 7 & 7 & 3 \\
8 & 1 & 0 & 4 & 5 & 4 & 7 & 8 & 6 & 8 & 1 \\
9 & 0 & 2 & 4 & 5 & 6 & 5 & 5 & 4 & 4 & 2 \\
10 & 1 & 3 & 3 & 3 & 5 & 3 & 4 & 6 & 5 & 4 \\
\hline
\end{tabular}

De um total de 281 acasalamentos observados, ocorreram apenas 5 entre machos e femeas de ate 4 dias de idade, machos de 3 dias com femeas de 2 e 4 dias e machos de 4 dias com femeas de 2,3 e 4 dias, representando 1,88 do total. Quando se consideram machos de 5 a 10 dias e femeas 
de 4 a 10 dias, ocorreram 210 acasalamentos, ou 74,78 do total.

$\mathrm{Na}$ FIGURA 5 verifica-se que 0 número de acasalamentos de machos de 3 e 4 dias foi significativamente maior que o de machos de 1 e 2 dias. Os maiores números de acasalamentos de machos ocorreram nas idades de 5 a 10 dias, diferindo de forma significativa das demais idades.

Na FIGURA 6 verifica-se que o número de acasalamentos de femeas de 2 dias foi significativamente maior que $o$ de femeas de 1 dia. os maiores números de acasalamentos de femeas ocorreram aos 5, 6, 8 e 9 dias, nao diferindo de 4 e 7 dias, e diferindo significativamente dos demais.

Deve-se considerar que os insetos tiveram apenas uma hora para mostrar o comportamento de cópula, uma vez que procurava-se determinar uma atratividade imediata, que poderia estar associada a uma maior liberaçáo de feromónios. Naturalmente, se esses insetos permanecessem juntos por um tempo maior, e na presença de alimentos, o número de cópulas seria maior. 


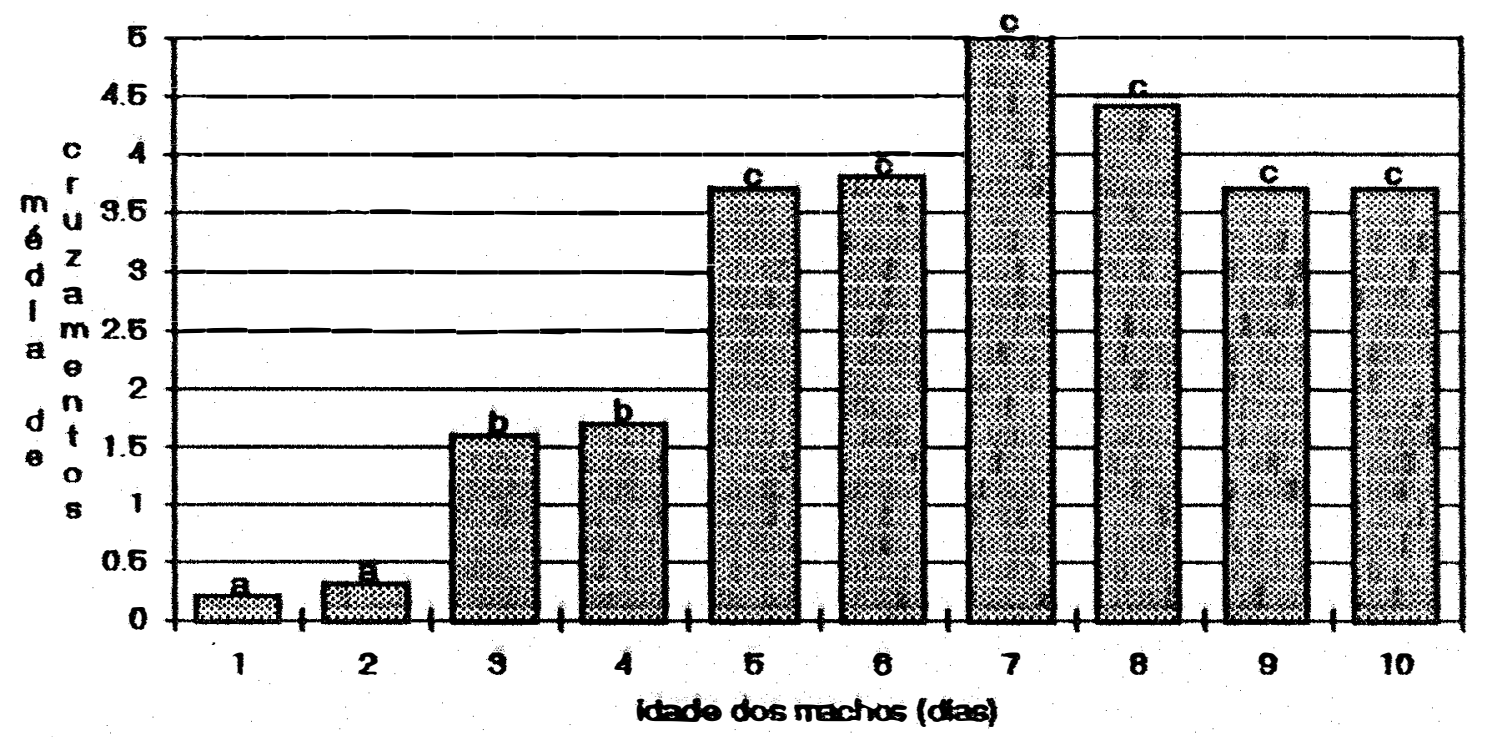

FIGURA 5. Número médio de acasalamentos de machos de $A$. fasciculatas, de 1 a 10 dias de idade (média de 10 repet1çбes). Temperatura $27 \pm 2^{\circ} \mathrm{C}$, Umidade relativa do ar $90 \pm 58$. Colunas com letras iguais nå diferiram pelo teste de Duncan a $58\left(F=19,66^{\star \star}, C V=22,0648\right)$.

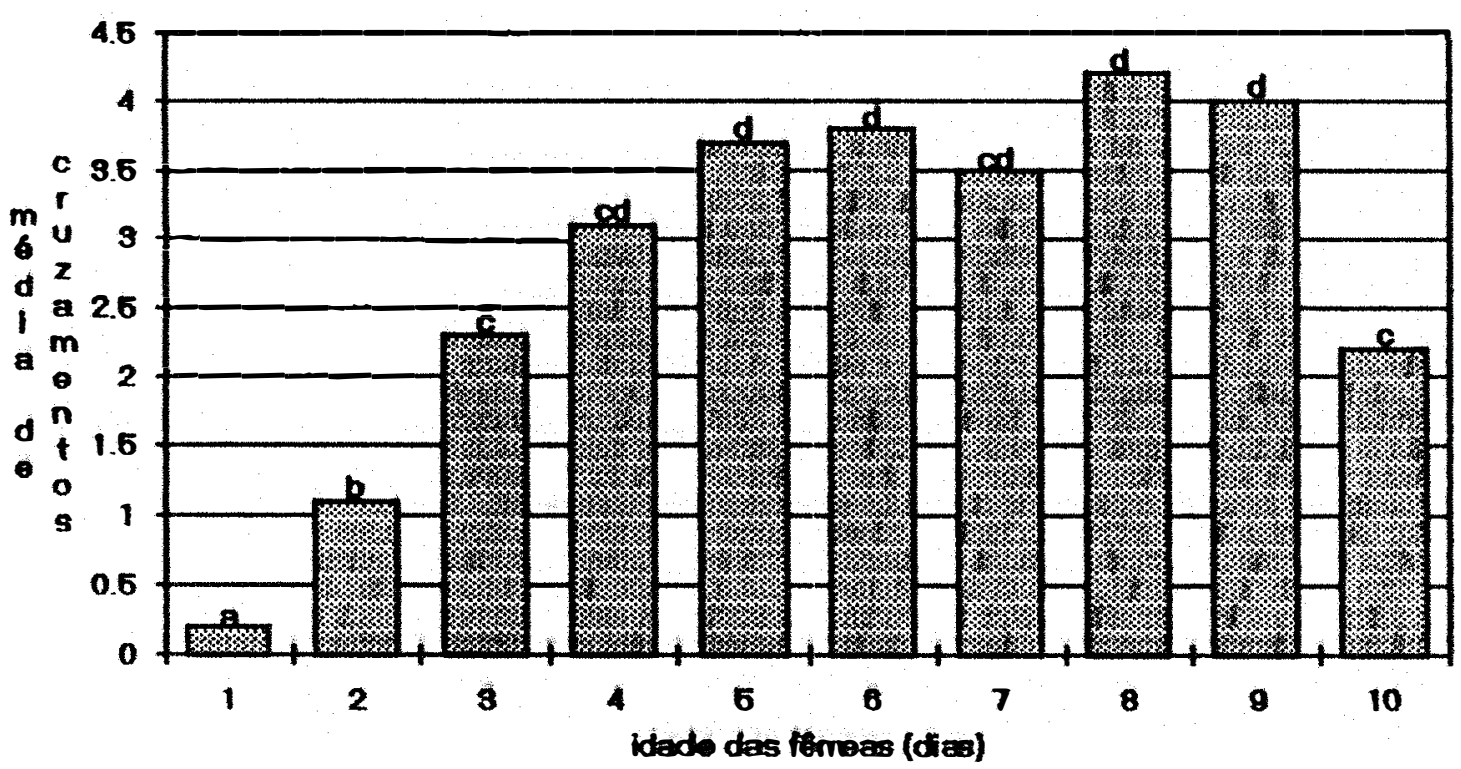

EIGURA 6. Número médio de acasalamentos de fémeas de $\boldsymbol{A}$. fasciculatas, de 1 a 10 dias de idade (médias de 10 repetiçoes). Temperatura $27 \pm 2{ }^{\circ} \mathrm{C}$, umidade relativa do ar $90 \pm 58$. Colunas com letras iguais ná diferiram pelo teste de Duncan a $58\left(F-12,35^{\star} \star, C V-22,0648\right)$. 


\subsection{Eerombntos}

\subsubsection{Bioensalos}

Em estudos preliminares, observou-se que a temperatura influi bastante na resposta do caruncho, sendo a melhor intensidade de resposta obtida à mesma temperatura em que os insetos foram criados, $27^{\circ} \mathrm{C}$. Verificou-se que 40 minutos foram suficientes para a escolha de até 1008 dos insetos, quando a atratividade foi suficientemente grande. Esse tempo foi maior que o utilizado por PHILLIPS \& BURKHOLDER (1981) para s. oxyzae, de 10 minutos.

Eoi mantida uma fotofase de 12 horas, iniciada às 7:00 horas, e verificou-se que a maior atividade do caruncho ocorreu entre 9:00 e 14:00 horas, sendo os bioensaios conduzidos entre 9:00 e 10:00 horas. Grande parte dos trabalhos, estudando respostas de colebpteros de grăos armazenados a feromonios, tem sido realizada no período da fotofase, por ser o período de maior atividade desses insetos.

A umidade relativa alta é essencial para o desenvolvimento do caruncho, conforme já verificaram PUZZI \& PEREIRA (1967). Neste estudo, verificou-se que os insetos mantidos nos tubos individuais, usados como fonte de atraçăo, năo sobrevivem mais que 4-5 dias se o algodåo 
colocado no tubo for mantido na umidade ambiente. A manutenção do algodâo em uma camara saturada de umidade por 24 horas, permitiu a sobrevivencia dos carunchos por ate 20 dias, fornecendo a umidade necessaria.

Verificou-se que a resposta era drasticamente reduzida, nos dias em que havia alteraçoes bruscas no clima, como temporais, e por isso evitou-se a realização de bioensaios nessas condiçoes. Segundo LANIER \& BURNS (1978), a sensibilidade às flutuaçoes da pressáo atmosferica pode ser o mecanismo que leva a reduçăo da resposta em bioensaios de laboratorio em tempo de tempestade, onde há alteraçoes barometricas.

o olfatometro $\theta$ as condiçoes utilizadas na condução dos bioensaios mostraram-se adequados para avaliaçăo de respostas de A. Easoicalatus à atraçâo por substancias volateis.

\subsubsection{Atratividade de voláteis de femeas adultas}

Os bioensaios usando femeas como fonte de atraçăo mostraram (TABELA 5) que estas nao atraíram fémeas de forma significativa. Foram testadas femeas de 6 a 9 dias atraindo femeas de 7 a 9 dias, e somente femeas de 9 dias atraíram mais que a testemunha, mas ainda assim a diferença năo foi significativa, devendo ainda ser considerado que apenas 328 
dos insetos se mostraram ativos, isto e, apresentaram algum tipo de resposta. A atividade obtida nesta serie de bioensaios foi de 38 t

TABELA 5. Respostas de femeas virgens de A. fasoioulatas de 7 a 9 dias, atraidas por volateis de femeas virgens de 6 a 9 dias (medias de 10 repetiços). Temperatura $27 \pm 2^{\circ} \mathrm{C}$, Umidade relativa do ar $90 \pm 58$

\begin{tabular}{|c|c|c|c|c|c|}
\hline \multicolumn{2}{|c|}{ TRATAMENTO } & & & SEM RESPOSTA & \\
\hline fonte & receptor & $E P^{1}$ & $\mathrm{EP}^{1}$ & $\mathrm{EP}^{2}$ & \\
\hline 6 & 7 & $17 \pm 4,2$ & $19 \pm 3,1$ & $64 \pm 4,5$ & 0,74 \\
\hline 7 & 7 & $16 \pm 4,0$ & $20 \pm 2,6$ & $64 \pm 5,8$ & 0,27 \\
\hline 7 & 8 & $21 \pm 4,3$ & $30 \pm 3,3$ & $49 \pm 5,3$ & 0,15 \\
\hline 8 & 8 & $15 \pm 3,4$ & $23 \pm 4,7$ & $62 \pm 5,1$ & 0,25 \\
\hline 8 & 9 & $17 \pm 2,6$ & $17 \pm 3,3$ & $66 \pm 4,0$ & 1,00 \\
\hline 9 & 7 & $22 \pm 5,7$ & $10 \pm 2,1$ & $68 \pm 6,6$ & 0,06 \\
\hline
\end{tabular}

Da mesma forma, fêmeas de 7 a 9 dias nấo atraíram machos de 7 a 9 dias de forma significativa (TABELA 6), e neste caso femeas de 7 e 8 dias atraíram mais machos que a testemunha, tendo a maior atraçăo ocorrido entre fêmeas e machos de 8 dias, sem diferença significativa entre as 
respostas, e com 53 dos insetos apresentando atividade. A porcentagem media de insetos ativos foi de 56 .

TABELA 6. Respostas de machos virgens de A. fascicolatus de 7 a 9 dias, atraidos por volateis de femeas virgens de 7 a 9 dias (medias de 10 repetiços). Temperatura $27 \pm 2^{\circ} \mathrm{C}$, Umidado relativa do ar $90 \pm 58$.

\begin{tabular}{|c|c|c|c|c|c|}
\hline \multicolumn{2}{|c|}{ TRATAMENTO } & \multirow{2}{*}{$\begin{array}{c}\text { FONTE } \\
\pm \\
\text { EP }^{1}\end{array}$} & \multirow{2}{*}{$\begin{array}{c}\text { TESTEMUNHA } \\
\pm \\
\text { EP }^{2}\end{array}$} & \multirow{2}{*}{$\begin{array}{c}\text { SEM RESPOSTA } \\
\pm \\
\text { EP }^{2}\end{array}$} & \multirow{2}{*}{$\mathrm{EROB}>\mathrm{T}$} \\
\hline fonte & receptor & & & & \\
\hline 7 & 7 & $36 \pm 5,6$ & $24 \pm 5,2$ & $40 \pm 4,7$ & 0,25 \\
\hline 7 & 8 & $32 \pm 3,9$ & $30 \pm 3,3$ & $38 \pm 3,9$ & 0,75 \\
\hline 8 & 8 & $31 \pm 5,5$ & $22 \pm 3,9$ & $47 \pm 8,3$ & 0,08 \\
\hline 9 & 8 & $23 \pm 5,4$ & $27 \pm 6,8$ & $50 \pm 5,2$ & 0,73 \\
\hline 9 & 9 & $20 \pm 3,9$ & $33 \pm 5,8$ & $47 \pm 6,3$ & 0,12 \\
\hline
\end{tabular}

Esses resultados năo indicam a ocorrencia de feromónios liberados pelas femeas, porém năo eliminam a possibilidade dos mesmos existirem. PHILLIPS \& BURKHOLDER (1981) observaram que a baixa concentraçăo pode ter impedido a obtençăo de prova experimental da existencia de. feromónios produzidos por femeas de $s$. oxpzae e segundo HEDIN et al.(1979), esse fato dificultou a prova da ocorrencia do feromonio emitido pelas femeas de Anthanomns 
grandis Boheman (Coleoptera: Curculionidae). Segundo SINGH (1993), o feromónio sexual de femeas de $A$. fascioulatus provoca somente comportamento de acasalamento em machos da especie.

\subsubsection{Atratividade de voláteis de machos adultos} Os bioensaios usando machos como fonte de atração, atraíram tanto femeas como machos. Na atração a machos (TABELA 7), somente em dois casos, machos de 6 e 9 dias atraindo machos de 8 dias, houve atraçăo maior pela testemunha, mas em ambos a diferença entre as respostas nåo foram significativas. No tratamento em que machos de 7 dias atralram os de 6 dias, apesar da resposta ser maior ao tratamento, tambem foi năo significativa.

Nos demais tratamentos, houve atraçăo dos machos, significativas a niveis inferiores a 5 . A porcentagem média de insetos ativos foi 618, maior que as apresentadas quando as femeas atraíam femeas (388) e machos (568). A preferencia dos machos ativos, nos tratamentos em que houve diferenças significativas entre a fonte de voláteis e a testemunha (FIGURA 7), indica que pelo menos 60 deles preferiram $\circ$ tubo com $\circ$ inseto, sendo atraidos pelos voláteis dos machos. 
TABELA 7. Respostas de machos virgens de A. Fasoloulatas de 6 a 10 dias, atraldos por volateis de machos virgens de 5 a 10 dias (medias de 10 repetiços). Temperatura $27 \pm 2^{\circ} \mathrm{C}$, Umidade relativa do ar $90 \pm 58$.

\begin{tabular}{|c|c|c|c|c|c|}
\hline \multicolumn{2}{|c|}{ TRATAMENTO } & \multirow{2}{*}{$\begin{array}{c}\text { EONTE } \\
\pm \\
\text { EP }^{1}\end{array}$} & \multirow{2}{*}{$\begin{array}{c}\text { TESTEMUNHA } \\
\pm \\
\text { EP }^{1} \\
\end{array}$} & \multirow{2}{*}{$\begin{array}{c}\text { SEM RESPOSTA } \\
\pm \\
\text { EP }^{1} \\
\end{array}$} & \multirow{2}{*}{$P R O B>T$} \\
\hline fonte & receptor & & & & \\
\hline 5 & 8 & $47 \pm 4,7$ & $20 \pm 4,2$ & $33 \pm 2,6$ & 0,01 \\
\hline 6 & 7 & $37 \pm 6,3$ & $13 \pm 2,1$ & $50 \pm 6,3$ & 0,01 \\
\hline 6 & 8 & $23 \pm 5,0$ & $42 \pm 6,1$ & $35 \pm 5,4$ & 0,08 \\
\hline 7 & 6 & $34 \pm 5,0$ & $22 \pm 2,0$ & $44 \pm 4,3$ & 0,09 \\
\hline 7 & 7 & $43 \pm 5,6$ & $17 \pm 3,0$ & $40 \pm 6,1$ & 0,00 \\
\hline 7 & 10 & $40 \pm 5,6$ & $18 \pm 4,2$ & $42 \pm 5,7$ & 0,02 \\
\hline 8 & 8 & $39 \pm 4,8$ & $22 \pm 4,7$ & $39 \pm 6,2$ & 0,04 \\
\hline 8 & 9 & $40 \pm 4,7$ & $25 \pm 2,7$ & $35 \pm 5,4$ & 0,02 \\
\hline 9 & 8 & $30 \pm 4,5$ & $36 \pm 3,7$ & $34 \pm 5,6$ & 0,34 \\
\hline 10 & 8 & $40 \pm 2,6$ & $25 \pm 3,4$ & $35 \pm 3,7$ & 0,01 \\
\hline
\end{tabular}




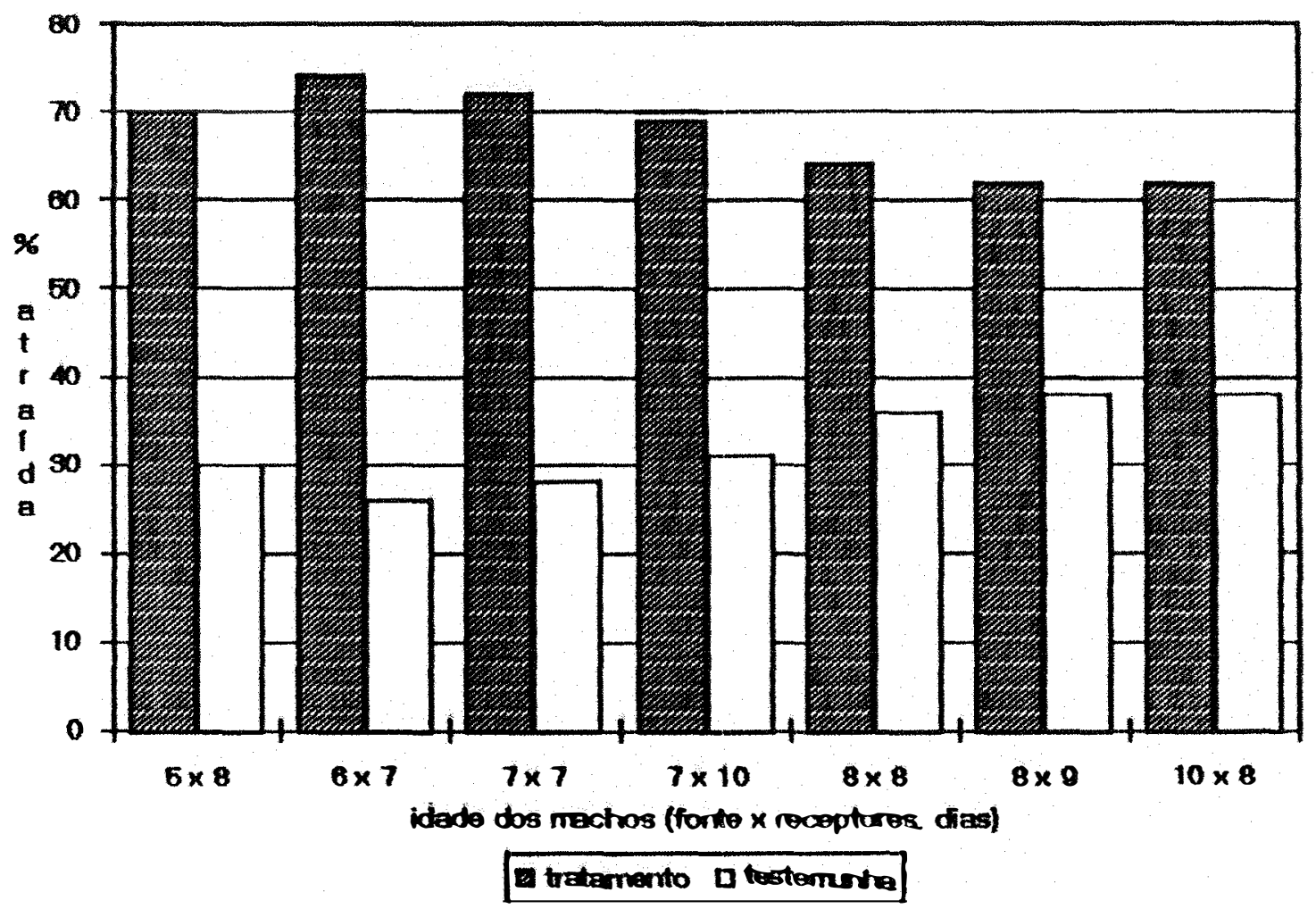

FIGURA 7. Respostas de machos ativos de A. fasciculatus de 8 a 10 dias de idade, atraidos por machos de 5 a 10 dias de idade (médias de 10 repetiçóes). Temperatura $27 \pm 2^{\circ} \mathrm{C}$, Umidade relativa do ar $90 \pm 5$. 
Na atração de femeas (TABELA 8), somente dois tratamentos nao apresentaram resultados significativos: machos de 2 dias atraindo femeas de 8 dias e machos de 7 dias atraindo femeas de 4 dias, embora o número de insetos atraidos pelo tratamento tenha sido maior que o atraido pela testemunha; em todos os outros tratamentos, houve respostas significativas em nível inferior a 5 de probabilidade. A porcentagem media de insetos ativos foi de 578, porem se forem considerados somente machos de 5 ou mais dias atraindo femeas de 7 ou mais dias, essa media aumenta para 688, maior que a ocorrida quando foram atraidos machos e quando femeas foram a fonte de atraçao, nas mesmas condiçôes de idade.

A atratividade de machos de 2 a 10 dias atraindo femeas de 8 dias, considerando apenas as femeas ativas (FIGURA B), aumenta Com a idade. Assim, machos de 2 e 3 dias atraíram menos de 70 das fomeas ativas, e a partir de 4 dias atralram mais de 80 delas, com exceçăo de machos de 6 dias, que atrairam 778. A maior atratividade, 978, foi obtida com machos de 10 dias. 
TABELA 8. Respostas de femeas virgens de A. Lascioulatas de 3 a 10 dias, atraidas por volateis de machos virgens de 2 a 10 dias (médias de 10 repetiçôes). Temperatura $27 \pm 2{ }^{\circ} \mathrm{C}$, Umidade relativa do ar $90 \pm 58$.

\begin{tabular}{|c|c|c|c|c|c|c|}
\hline \multicolumn{2}{|c|}{ TRATAMENTO } & $\begin{array}{c}\text { FONTE } \\
\pm\end{array}$ & $\begin{array}{c}\text { TEST EMONTA } \\
\pm\end{array}$ & SEM & $\begin{array}{l}\text { RESPOSTA } \\
\pm\end{array}$ & PROB $>T$ \\
\hline fonte & receptor & $\mathrm{EP}^{2}$ & EXP ${ }^{1}$ & & EP $^{1}$ & \\
\hline 2 & 8 & $27 \pm 2,6$ & $25 \pm 2,7$ & & $48 \pm 3,6$ & 0,62 \\
\hline 3 & 8 & $27 \pm 4,7$ & $13 \pm 2,1$ & & $60 \pm 5,4$ & 0,02 \\
\hline 4 & 8 & $25 \pm 4,3$ & $5 \pm 1,7$ & & $70 \pm 4,2$ & 0,00 \\
\hline 5 & 8 & $53 \pm 5,0$ & $4 \pm 1,6$ & & $43 \pm 4,7$ & 0,00 \\
\hline 6 & 6 & $40 \pm 3,3$ & $14 \pm 2,2$ & & $46 \pm 5,0$ & 0,00 \\
\hline 6 & 8 & $54 \pm 3,4$ & $16 \pm 4,5$ & & $30 \pm 4,9$ & 0,00 \\
\hline 7 & 4 & $22 \pm 4,7$ & $17 \pm 4,7$ & & $61 \pm 7,7$ & 0,38 \\
\hline 7 & 7 & $47 \pm 5,6$ & $22 \pm 3,6$ & & $31 \pm 5,9$ & 0,01 \\
\hline 7 & 8 & $72 \pm 3,9$ & $9 \pm 2,3$ & & $19 \pm 3,1$ & 0,00 \\
\hline 8 & 3 & $21 \pm 2,8$ & $12 \pm 1,3$ & & $67 \pm 3,3$ & 0,01 \\
\hline 8 & 5 & $38 \pm 4,7$ & $10 \pm 2,6$ & & $52 \pm 7,0$ & 0,00 \\
\hline 8 & 7 & $38 \pm 5,7$ & $3 \pm 1,5$ & & $59 \pm 6,2$ & 0,00 \\
\hline 8 & 8 & $60 \pm 4,2$ & $11 \pm 2,3$ & . & $29 \pm 5,7$ & 0,00 \\
\hline 8 & 10 & $70 \pm 2,6$ & $13 \pm 3,0$ & & $17 \pm 3,7$ & 0,00 \\
\hline 9 & 8 & $70 \pm 5,2$ & $8 \pm 2,5$ & & $22 \pm 5,3$ & 0,00 \\
\hline 9 & 9 & $37 \pm 2,6$ & $15 \pm 3,4$ & & $48 \pm 5,3$ & 0,00 \\
\hline 10 & 8 & $72 \pm 4,2$ & $2 \pm 1,3$ & & $26 \pm 5,0$ & 0,00 \\
\hline
\end{tabular}




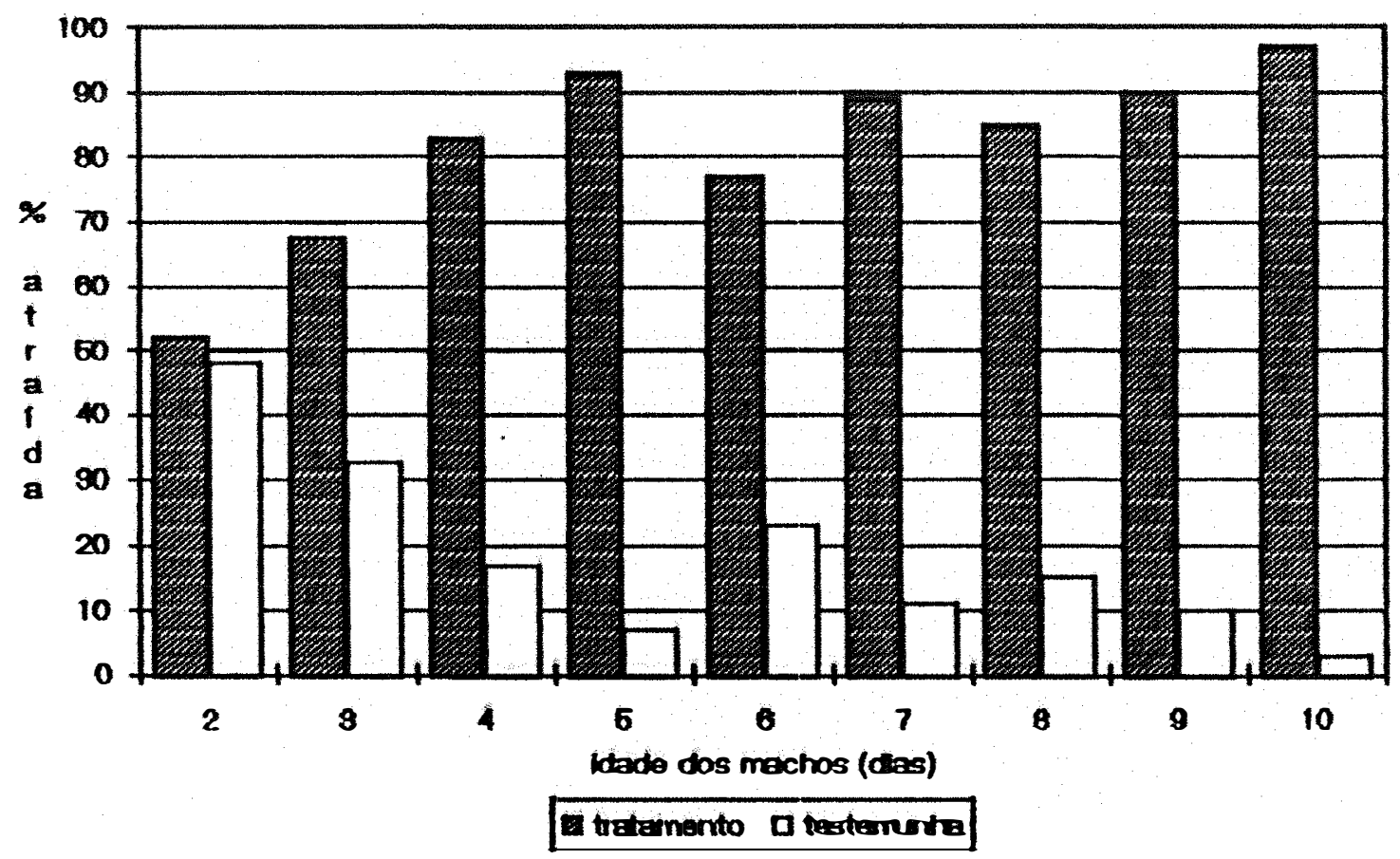

FIGURA 8. Respostas de femeas ativas de $\mathbf{A}$. fasolonlatus de 8 dias de idade, atraidas por machos de 2 a 10 dias de idade (médias de 10 repetiços). Temperatura $27 \pm 2^{\circ} \mathrm{C}$, Umidade relativa do ar $90 \pm 5$.

PHILLIPS \& BURKHOLDER (1981) consideraram que discos de ensaio bacteriano que permaneciam em um pequeno frasco, com um adulto de $\mathbf{s}$. oryzae por 7 dias, continham 0 feromonio equivalente ao liberado por 7 insetos em 1 dia. Neste estudo, por estar o inseto presente, nå foi possível verificar se a atratividade resultou da idade do inseto no dia do bioensaio, ou do feromonio acumulado no período, 
devendo ter ocorrido uma soma dos dois efeitos. Entretanto, pelo pequeno número de acasalamentos ocorridos com machos de 1 e 2 dias, pode-se considerar que a emissato de feromónios nesses dois dias deve ser muito pequena. A produção de feromónios deve iniciar-se ou pelo menos atingir um nivel mais alto a partir de 3 dias de idade.

Como o limiar de resposta de insetos a feromónios e muito baixo, o aumento da concentraçăo do mesmo tem pouco efeito na resposta. WALGENBACH \& BURKHOLDER (1986) verificaram que femeas de s. zeamats respondem significativamente a concentraçoes a partir de $1 \mathrm{ng}$ e machos a partir de $10 \mathrm{ng}$, provavelmente por estarem acostumados a baixas concentraçôes de feromónio, por eles produzido. Ainda segundo esses autores, a produçăo diária de feromónios por inseto entre 1 e 10 dias de idade foi de cerca de $27 \mathrm{ng}$, suficiente portanto para atrair machos e femeas.

A atratividade de machos de 8 dias, para femeas de 3 a 10 dias (FIGURA 9), considerando-se os insetos ativos, mostra que 64 das fomeas de 3 dias, a menor idade em que houve atraçăo significativa, foram atraidas. A. partir de 5 dias, quando a atraçăo foi de 798, esta manteve-se acima de 80. As femeas de 7 dias foram as mais atraidas, 938, havendo uma diminuiçăo com 9 e 10 dias. 0 período de maior resposta das femeas e machos estao assim 
de acordo com o periodo em que apresentam maior número de copulas.

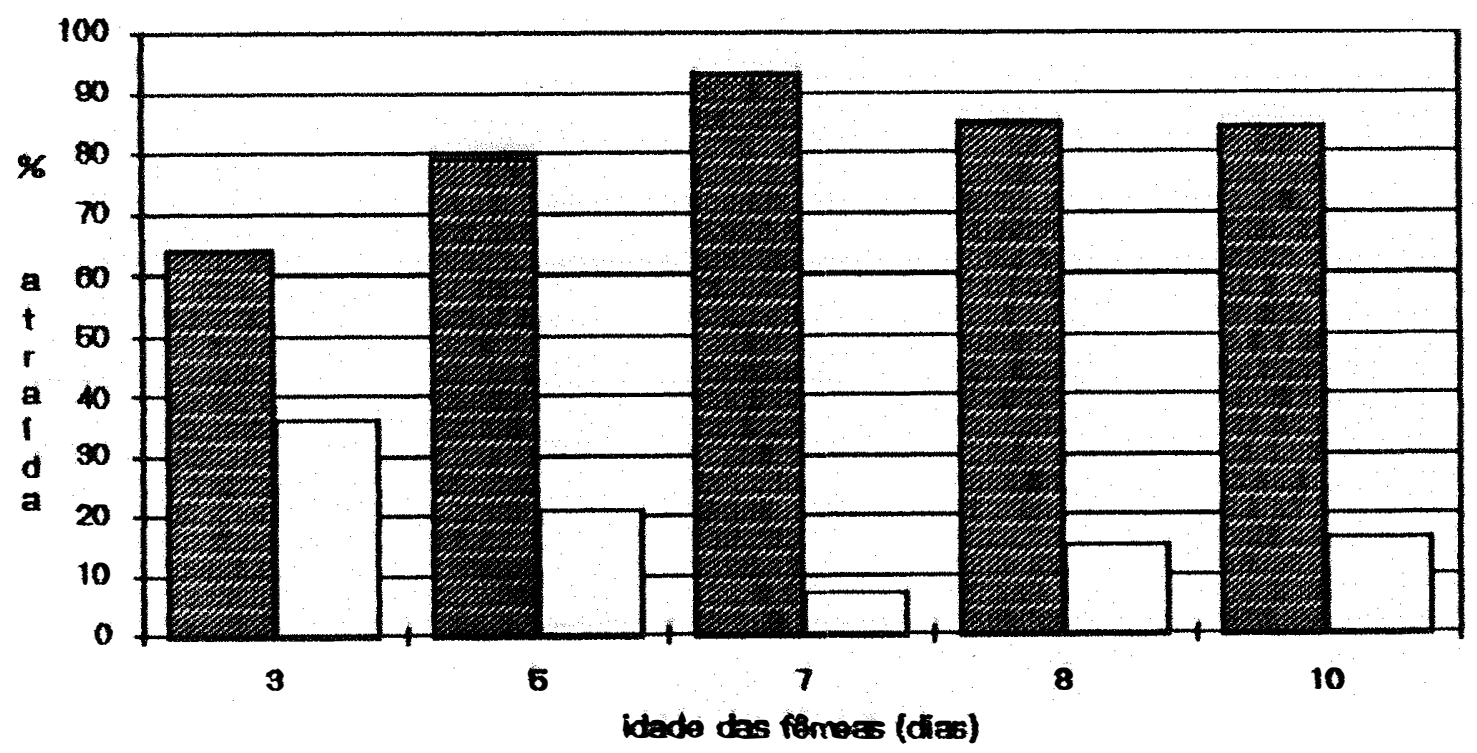

Q tratamento a testamenta

FIGURA 9. Resposta de fémeas ativas de A. fascionlatas de 3 a 10 dias de idade, atraídas por machos de 8 dias (médias de 10 repetições). Temperatura $27 \pm 2^{\circ} \mathrm{C}$, Umidade relativa do ar $90 \pm 58$.

Estes resultados evidenciam a existencia de um feromónio de agregaçăo, produzido por machos de $\mathbf{A}$. 
constatação confirma a proposição de BURKHOLDER (1982), de que geralmente insetos de grăos armazenados de vida superior a 1 mes, e que necessitam de alimentaçao para reproduzir, apresentam feromonios de agregaçao, produzidos pelos machos.

A viabilidade da utilizaçăo dessas substancias na detecçăo ou controle desta especie depende ainda de estudos visando sua identificaçăo, síntese e posteriormente, bioensaios para avaliar o comportamento desse inseto a quantidades conhecidas do feromonio, a determinaçăo do tipo de armadilha mais eficiente, e a forma de sua utilizaçăo. 


\section{CONCLUSÕEs}

1. O ciclo de A. fasciculatus, de ovo a adulto, em cafe do cultivar Mundo Novo com 128 de umidade inicial, a $27 \pm 2^{\circ} \mathrm{C}$, $90 \pm 58$ UR, e fotofase de 12h, varia de 57 a 97 dias, com uma media de $72,4 \pm 1,0$ dias.

2. A primeira cópula de A. Iascicalatas, entre machos e femeas de até 5 dias de idade, ocorre entre femeas de 2 dias e machos de 3 dias.

3. o olfatometro de dupla escolha e o metodo utilizado săo eficientes para a avaliaçăo do comportamento de adultos de A. fascicalatas em relaçăo a substâncias voláteis.

4. Machos e femeas virgens de A. Easoioalatas săo atraídos pelos volateis de machos virgens, evidenciando a existencia nesta especie de feromonio de agregaçăo, produzido por machos. 


\section{REFEREANCIAS BIBLIOGRÁFICAS}

ARSURA, E. \& ACCINELLI, U. I feromoni di sintesi nella tecnica del monitoraggio. Informatore Eitopatologico, Bologna, $40(6): 5-11,1990$.

ARSURA, E. \& ACCINELLI, U. La "Cattura di massa" nella lotta contro gli insetti. Informatore Fitopatologioo, Bologna, $11(9): 11-16,1991$.

AUTUORI, M. Dados biologicos sobre o Araeoeras fasciculatus (De Geer)(Col. Anthribidae). Revista de Entomologia, Sào Paulo, 1(1):52-61, 1931

BAKER, T.C. \& CARDE, R.T. Techniques for Behavioral Bioassays. In: HUMMEL, H.E.; MILLER, T.A., (eds). Teohniques in Pheromone Researoh. New York, SpringerVerlag, 1984, p.45-73. 
BITRAN, E.A. Avaliaçăo experimental de prejuízos causados pelo caruncho-do-cafe, Araeceras fascioulatas (De Geer, 1775) (Coleoptera, Anthribidae), em cafe beneficiado armazenado. Arquivos do Instituto Biológico, săo paulo, $40(4): 343-355,1973$.

BLACKWELDER, R.E. Cheoklist of the ooleopterous inseots of Mexioo, Central Amerioa, The Indies and south Amerioa. Washington, Smithsoniam Institution, 1957. 1492 p. (Bulletin 185)

BORDEN, J.H.; DOLINSKY, M.G.; CHONG, L. VERIGIN, V.; PIERCE， H.D.,JR.; OEHLSCHLAGER, A.C. Aggregation pheromone in the rusty grain beetle, cryptolestes ferrugineas (Coleoptera: Cucujidae). Canadian Entomologist, Ottawa, $111(6): 681-688,1979$.

BRICENO-IRAGORRY, L. Nota sobre Araecerus fasciculatus De Geer, coleoptero atacante del grano del cafe. Boletin do Laborator 10 Luis Razett1, Caracas, 1(1):2-14, 1940.

BURKHOLDER, W.E. Reproductive biology and communication among grain storage and warehouse beetles. Journal of the Georgia Entomologioal sooiety, Athens, 17(4):110 (suppl. 2), 1982. 
BURKHOLDER, W.E. \& DICKE, R.J. EVidence of sex pheromones in females of several species of Dermestidae. Journal of Economio Entomology, College Park, 59(3):540-543, 1966.

BURKHOLDER, W.E. \& MA, M. Pheromones for monitoring and control of stored-product insects. In: Annual Reviev of Entomology, Palo Alto, 30:257-272, 1985.

CABAL CONCHA, A. Biologia y control del gorgojo del cafe: Araecerus fasotoulatus De Geer, Fam.: (Anthribidae) en Barranquilla, Colombia. Revista da Faculdade Naolonal de Agronomia, Medellin, 17(49):49-72, 1956.

CAMPION, D.G. Survey of pheromone uses in pest control. In: HUMMEL, H.E. \& MILLER, T.A., (eds). Techniques in Pheromone Research. New York, Springer-Verlag, 1984, p. 405-449.

CHAMBERS, J. Overview on stored-product insect pheromones and food attractants. Journal of the Kansas Entomological soolety, Manhattan, 63(4):490-499, 1990 
CHAMBERS, J.; MORGAN, C.P.; WHITE, P.R.; MORI, K.; FINNEGAN, D.E.; PINNIGER, D.B. Rust-red grain beetle, Cryptolestes ferruglneus, and flat grain beetle, Cryptolestes prsilizs: Antennal and behavioral responses to synthetic components of their aggregation pheromones. Journal of Chemical Eoology, New York, $16(12): 3353-3372,1990$.

CHILDERS, C.C. \& WOODRUFE, R.E. A bibliography of the coffee bean weevil Araeceras fasoloalatus (Coleoptera: Anthribidae). Bulletin of The Entomological soolety of Amertca, College Park, 26(3):384-394, 1980.

COFFELT, J.A. \& BURKHOLDER, W.E. Reproductive biology of the cigarrete beetle, rastoderma serr10orne. I. Quantitative laboratory bioassay of the female sex pheromone from females of different ages. Annals of the intomologioal soatety of Anertoa, College Park, $65(2): 447-450,1972$.

EL SAYED, M.T. On the biology of Araecerus fasoloulatus De Geer (Col., Anthribidae) with special reference to the effects of variations in the nature and water content of the food. Annale of Applied of Blology, London, $22(3): 557-577,1935$. 
EL SAYED, M.T. The morphology, anatomy and biology of Araecerus fasoioulatus De Geer (Coleoptera: Anthribidae) Bulletin de la soolété Fouad ler. d'Entomologie, Cairo, 24:82-151, 1940.

FAVERO, S.; SALGADO, L.O.; VILELA, E.F.; PIlli, R.A. Resposta olfativa de sitophilus zeamais Motsch. (Coleoptera: Curculionidae) ao feromónio sintético de agregação sitophilure. Anais da sociedade Entomológica do Brasil, Londrina, 22(3):427-432, 1993

FIGUEIREDO JR, E.R. O controle do caruncho-das-tulhas. B1ológico, Sào Paulo, 23(10):197-200, 1957.

FINNEGAN, D.E. \& CHAMBERS, J. Identification of the sex pheromone of the Guernsey carpet beetle, Anthrenns sarnious Mroczkowski (Coleoptera: Dermestidae). Journal of Chem1cal Ecology, New York, 19(5):971-983, 1993.

FONSECA, J.P. O caruncho-das-tulhas do cafeeiro. Blológ1co, Så Paulo, 1(10):368-369, 1935.

GECAN, J.S.; BANDLER, R.; ATKINSON, J.C. Microanalytical quality of imported green coffee beans. Journal of Food Protection, (s.1.), 51(7):569-570, 1988. 
GONÇALVES, L.I.; BITRAN, H.V.; BITRAN, E.A. Contribuição ao estudo da biologia do caruncho-do-cafe Araeceras fasctoulatus (De Geer, 1775) (Coleoptera, Anthribidae). Arquivos do Instituto Biológioo, Săo Paulo, $43(3 / 4): 81$ $88,1976$.

HAMMACK, L. \& BURKHOLDER, W.E. Circadian rhythm of sex pheromone-releasing behaviour in females of the dermestid beetle, Trogoderona glabrum: regulation by photoperiod. Journal of Inseot Physiology, London, $22(3): 385-388,1976$.

HAMMACK, L.: MA, M.: BURKHOLDER, W.E. Sex pheromonereleasing behaviour in females of the dermestid beetle, Trogoderma glabrwn. Journal of Inseot Physiology, London, $22(4): 555-561,1976$.

HECKER, E. B BUTENANDT, A. Bombykol revisited - reflections on a pionering period and on some of its consequences. In: HUMMEL, H.E. M M LleR, T.A., (eds). Teohniques in Pheromone Researoh. New York, Springer-Verlag, 1984, p. 1-44.

HEDIN，P.A.; MCKIBBEN， G.H.; MITCHELL，E.B.; JOHNSON，W.L. Identification and field evaluation of the compounds comprising the sex pheromone of the female boll weevil. Journal of Chemical Eoology, New York, 5(4): 617-627, 1979. Apud PHILLIPS \& BURKHOLDER (1981). 
HEMPEL, A. Praga do cafe. Boletim de Agrioultura, Sao Paulo, 2(4):265-268, 1901.

HUMMEL, H.E. Preface. In: HUMMEL, H.E. \& MILleR, T.A., (eds). Teohniques in Pheromone Researoh. New York, Springer-Verlag, 1984, p.VII-IX.

IMENES, S.D.L.; ZORZENON, F.J.; BERGMANN, E.C.; SILVA, L. E.F.R. Ocorrencia de Araecerus fasctoulatus (Coleoptera: Anthribidae) em frutos de Raphia pedmodlata Beauv. In: CONGRESSO BRASILEIRO DE ELORICULTURA E PLANTAS ORNAMENTAis, Recife, 1993. Resumos. Recife, Sociedade Brasileira de Floricultura e Plantas Ornamentais, 1993. s.p.

KARLSON, P. \& LUSCHER, M. 'Pheromones': a new term for a class of biologically active substances. Nature, London, $183(1): 55-56,1959$.

KUWAHARA, Y. \& NAKAMURA, S. (Z)-5- and (E)-5-undecenoic acid: identification of the sex pheromone of the varied carpet beetle Anthrenus vexbasot (L.) (Coleoptera: Dermestidae). Applied Entomology and zoology, Tokyo, 20:354-356, 1985. Apud FINNEGAN \& CHAMBERS (1993). 
LANIER, G.N. \& BURNS, B.W. Barometric flux: effects on the responsiveness of bark beetles to aggregation attractants. Journal of Chemical Eoology, New York, 4(2):139-147, 1978. Apud Review of Applied Entomology, London, 66(10):597, 1978. (Resumo 4828).

LAVABRE, E.M. \& DECAZY, B. Contribution a l'etude des problèmes posés par le stockage des cafés dans les pays de production. Primieres donnees sur le comportement de 1'Araecerus fascionlatus à temperature et humidité controlees. Café Cacao Thé, Paris, 12(4):321-342, 1968.

LEVANTAMENTO SISTEMATICO DA PRODUÇAO AGRICOLA, RIO de Janeiro, 6(4):23, 1994 .

MILLAR, J.G.; PIERCE, H.D., Jr.; PIERCE, A.M.; OEHLSCHLAGER, A.C.; BORDEN, J.H.; BARAK, A.V. Aggregation pheromones of the flat grain beetle, Cryptolestes pasillas (Coleoptera: Cucujidae). Journal of Chemical Boology, New York, 11(8):1053-1070, 1985a.

MILLAR, J.G.; PIERCE, H.D., Jr.; PIERCE, A.M.; OEHLSCHLAGER, A.C.; BORDEN, J.H. Aggregation pheromones of the grain beetle, Cryptolestes turoious (Coleoptera: Cucujidae). Journal of Chemioal Boology, New York, $11(8): 1071-1081,1985 b$. 
MUELLER, D.; PIERCE, L.; BENEZET, H.; KRISCHIK, V. Practical application of pheromone traps in food and tobacco industry. Journal of the Kansas Entomological sooiety, Manhattan, 63(4): 548-553, 1990.

OBENG-OFORI, D. \& COAKER, T.H. Some factors affecting responses of four stored products beetles (Coleoptera: Tenebrionidae \& Bostrichidae) to pheromones. Bulletin of Entomological Research, London, 80:433-441, 1990.

PAIVA, M.R. \& PEDROSA-MACEDO, J.H. Eeromonas de Insetos. Curitiba, Secretaria de Estado do Planejamento do Paraná/Agencia Alemâ de Cooperaçăo Técnica, 1985. 84p.

PENA, A.; KELLY, D.R.; SZAUMAN-SZUMSKI, C.; CAMPOS, M. Optimization of bioassay conditions for the olive bark beetle, Phloeotribus scarabaeoides. Entomologia Experimentalis et Applioata, Amsterdan, 63(1):81-86, 1992 .

PHILLIPS, J.K. \& BURKHOLDER, W.E. Evidence for a maleproduced aggregation pheromone in the rice weevil. Journal of Economic Entomology, College Park, $74(5): 539-542,1981$. 
PHILLIPS, J.K.; MILLER, S.P.F.; ANDERSEN, J.E.; FALES, H.M.; BURKHOLDER, W.E. The chemical identification of the granary weevil aggregation pheromone. Tetrahedron Letters, London, $28(49): 6145-6146,1987$.

PIERCE, A.M.; BORDEN, J.H.; OEHLSCHLAGER, A.C. Effects of age and population density on response to beetle and food volatiles by 0 . surinamensis and 0 . meroator (Coleoptera: Cucujidae). Environmental Entomology, College Park, 12(6):1367-1374, 1983.

PIERCE, H.D., Jr.; PIERCE, A.M.; JOHNSTON, B.D., OEHLSCHLAGER, A.C.: BORDEN, J.H. Aggregation pheromone of the square-necked grain beetle, Cathartas quadrioollis (Guer.). Journal of Chemical koology, New York, 14(12): 2169-2184, 1988 .

PIERCE, H.D., Jr.; PIERCE, A.M.; MILLAR, J.G.; WONG, J.W.; VERIGIN, V.G.; OEHLSCHLAGER, A.C.; BORDEN, J.H. Methodology for isolation and analysis of aggregation pheromones in the genera Cyptolestes and oryzaephilus (Coleoptera: Cucujidae). Proceedings of the Third International Working Conference on stored-Produot Entomology, Manhattan, Kansas, p.121-137. 1984. Apud CHAMBERS (1990) 
PUZZI, D. \& PEREIRA, H.F. Dados preliminares sobre estudos de ecologia do caruncho-do-cafe - Araecerms fascicalatas De Geer. Blolbgloo, Săo Paulo, 33(5):97$101,1967$.

RANGASWAMY, J.R. \& SASIKALA, V.B. Sex pheromone properties of $\mathrm{z}-2$, noneyl propionate isolated from virgin females of red flour beetle, Tribolitm astanemn (Coleoptera). Ind1an Journal of Experimental B1ology, 29(3) 263-266, 1991. Apud Reviek of Agrioultural Entomology, London, $80(2): 178,1992$. (Resumo 1531).

REIS, P.R. \& SOUZA, J.C. Pragas do cafeeiro. In: RENA, A. B., Malavolta, E., Rocha, M.: Yamada, T. eds. cultura do Cafeeiro: Fatores que afetam a produtividade. Potafos, Piracicaba, 1986, p.323-378.

SHOREY, H.H. Animal communioation by pheromones. New York, Academic Press, 1976. 167p.

SILVA, A.G.d'A.; GONÇALVES, C.R.; GALVAO, D.M.; GONÇALVES, A.J.L.; GOMES, J.; SILVA, M.N.; SIMONI, L. Quarto catálogo dos inseto que vivem nas plantas do Brasil. seus parasitos e predadores. Parte II, Tomo 1, Insetos, hospedelros e inimigo naturais. Rio de Janeiro, Ministério da Agricultura, 1968. 622p. 
SILVEIRA NETO, S. \& NAKANO, O. Teste de atratividade de Lastoderna serricome (F.) com o feromonio "Serrico". In: Congresso Brasileiro de Entomologia, 9, Londrina, 1984. Resumos. Londrina, Sociedade Entomológica do Brasil, 1984 . p.317.

SILVERSTEIN, R.M.; RODIN, J.O.; BURKHOLDER, W.E.; GORMAN, J.E. Sex attractant of the black carpet beetle. soienoe, washington, 157:85-87, 1967.

SINGH, K. Evidence of male and female of coffee bean weevil, Araeceres Fasciculatus (Deg)(Coleoptera: Anthribidae) emitted aggregation and sex pheromones. Crop Researoh (Hysar), 6(1):97-101, 1993. Apud Reviev of Agrioultural Entomology, London, $82(7): 769,1994$. (Resumo 6707).

TREMATERRA, P. Pheromone trapping and mating disruption leading to insectistasis. (Proceedings of a scientific Congress, Barcelona, Spain, 25-28 of October, 1988). Boletin de sanidad Vegetal, Madrid, 17 (Fuera de serie) : 495-510, 1989 .

VICK, K.W. , BURKHOLDER, W.E., ; GORMAN, J.E. Interespecific response to sex pheromones of Trogoderma species (Coleoptera: Dermestidae). Annals of the Entomologioal Society of Amerioa, College Park, 63(2):379-381, 1970. 
VILELA, E.F. \& DELLA LUCIA, T.M.C. Feromónios de insetos (blologia, guimioa e emprego no manejo de pragas). Viçosa, Imprensa Universitária - UFV, 1987. 155p.

WALGENBACH, C.A. BURKHOLDER, W.E. Eactors affecting the response of the maize weevil, sttophilns zeamats (Coleoptera: Curculionidae), to its aggregation pheromone. Environmental Entomology, College Park, $15(3): 733-738,1986$. 